
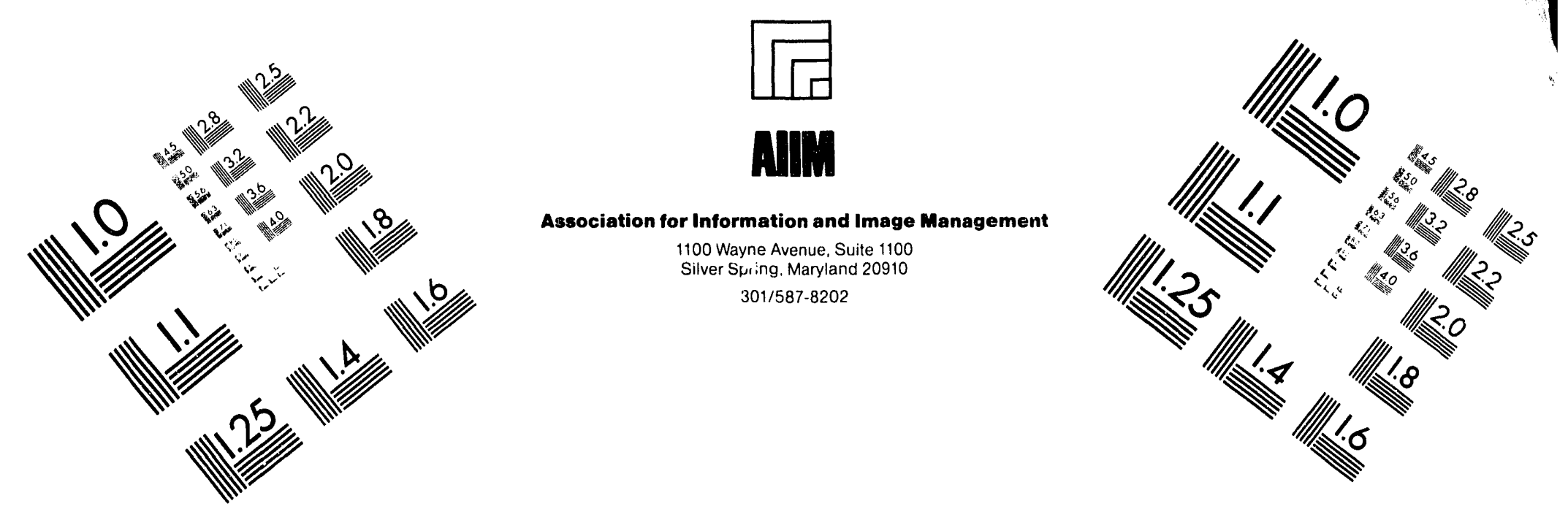

\title{
Centimeter
}

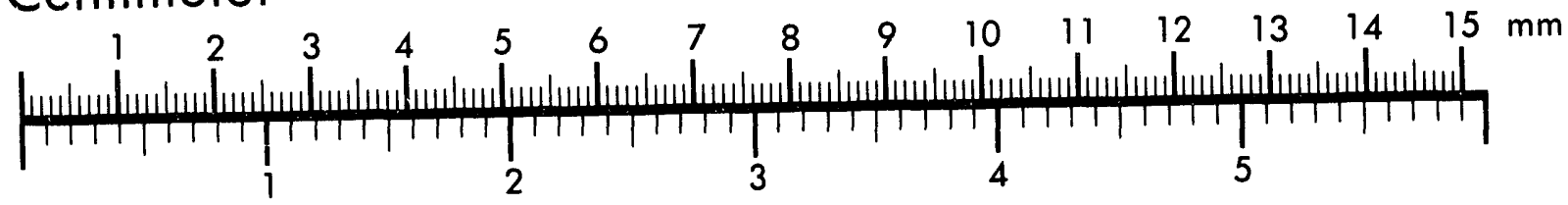
Inches
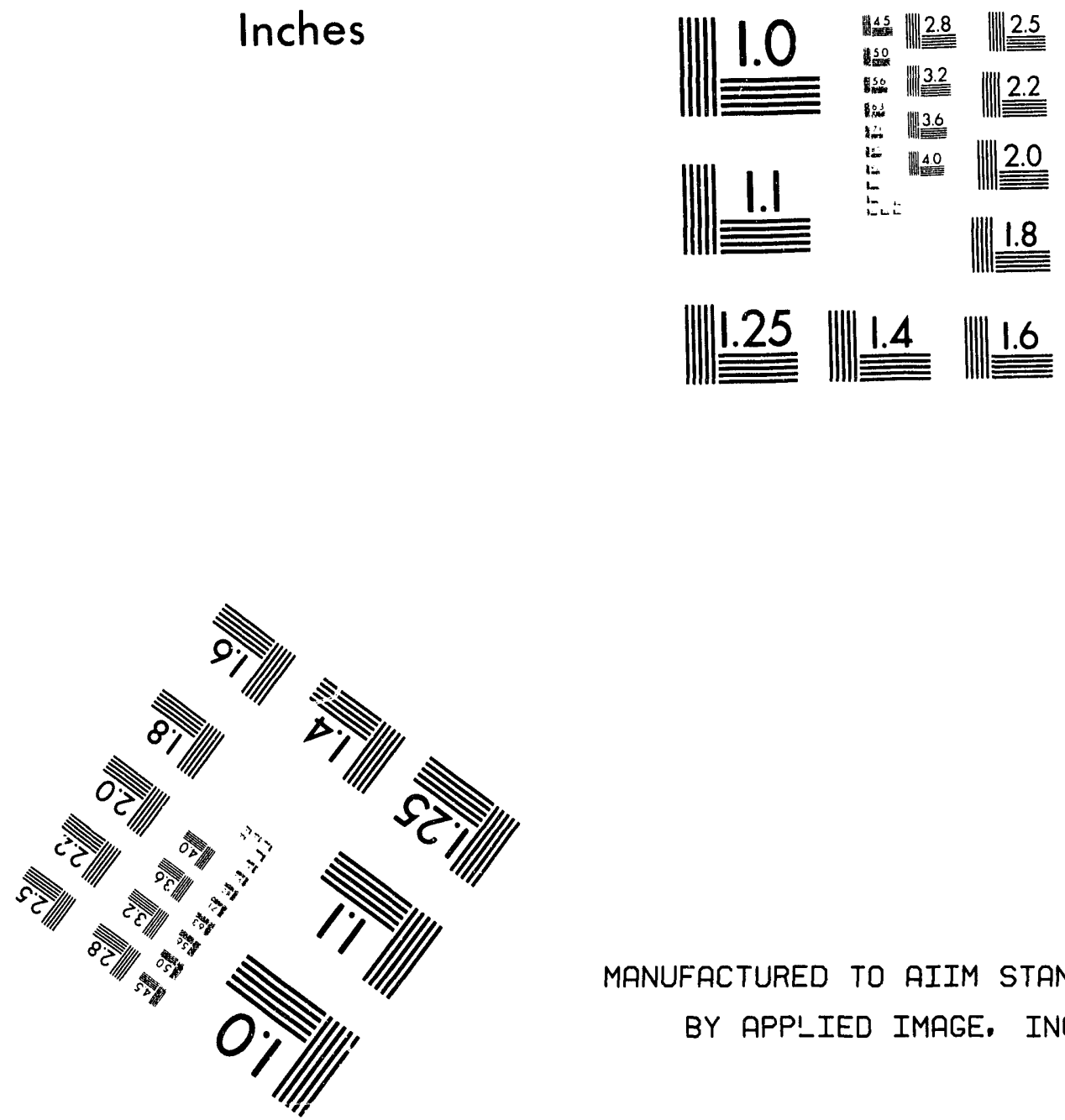

MANUFACTURED TO AIIM STANDARDS

BY APPIIED IMAGE. INC.

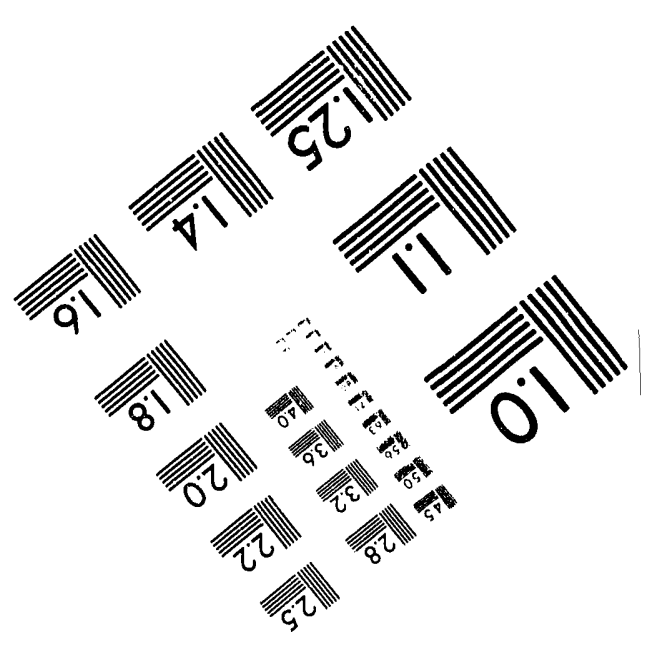



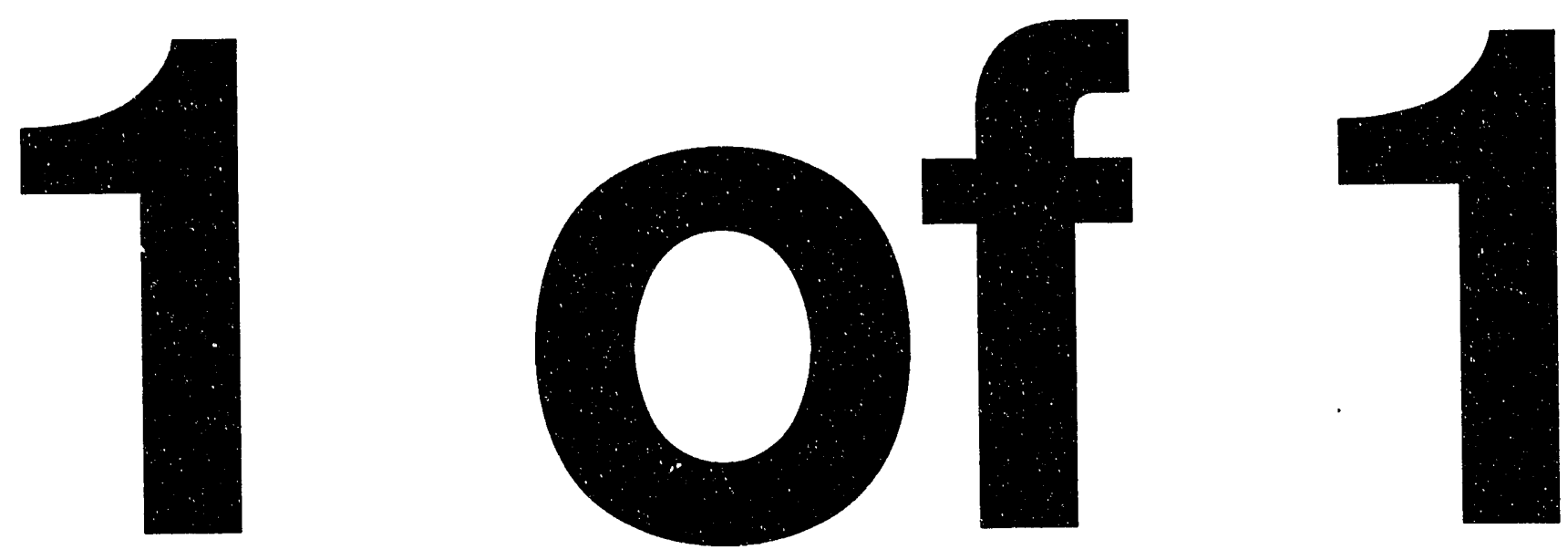
WHC-EP-0576

Revision 0

UC-600

\section{Assessment of Gas Accumulation and Retention - Tank 241-SY-101}

R. T. Alleman

Pacific Northwest Laboratory

T. M. Burke

D. A. Reynolds

D. E. Simpson

Westinghouse Hanford Company

Date Published

March 1993

Prepared for the U.S. Department of Energy

Environmental Restoration and

Waste Management

\section{9) Westinghouse P.O. Box 1970 \\ (V) Hanford Company Richland, Washington 99352}

andions and Engineering Contractor for the

Hanford Operations and Engineering Contractor tor the 10930 


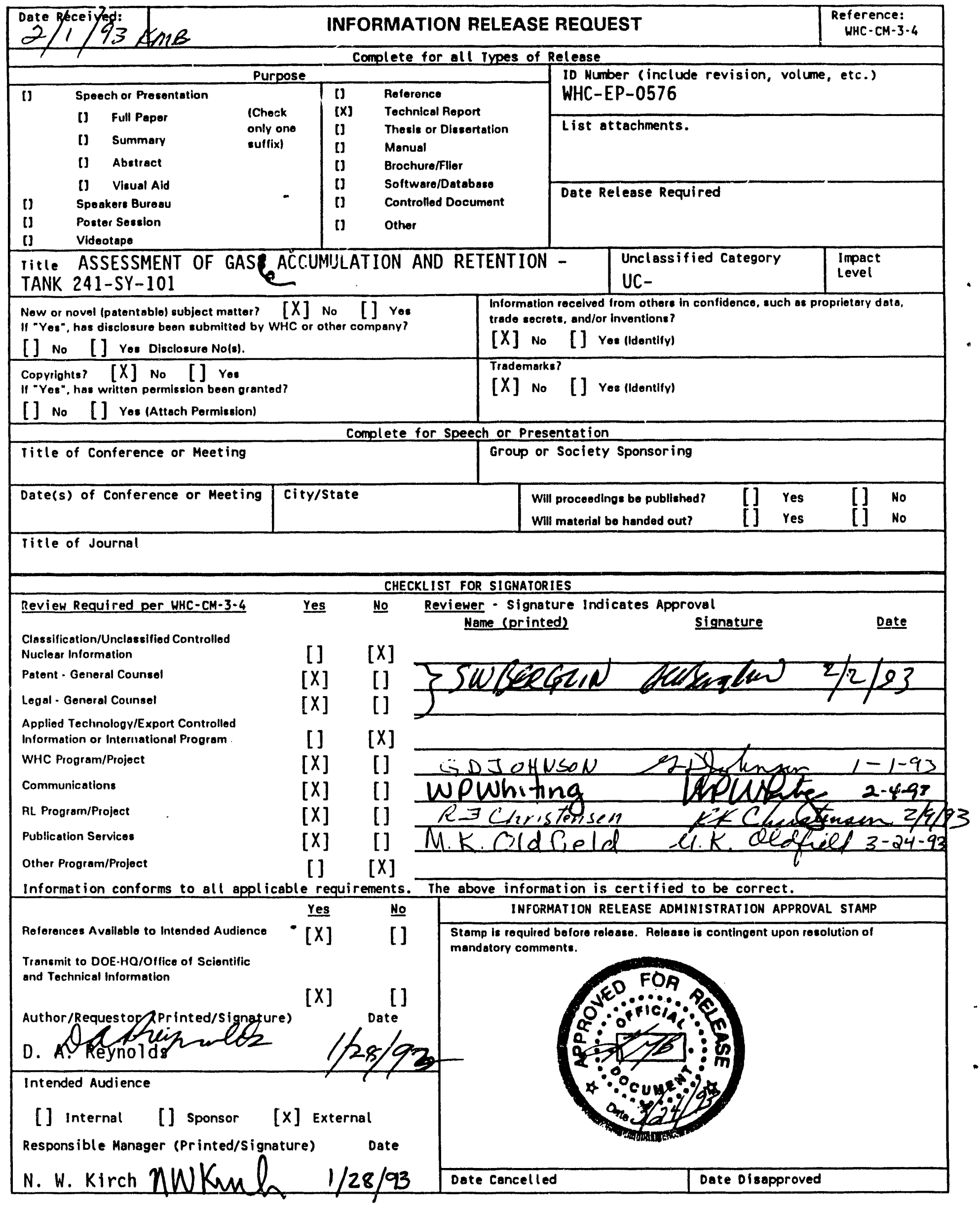


WHC-EP-0576

Document Title:

Prepared by:

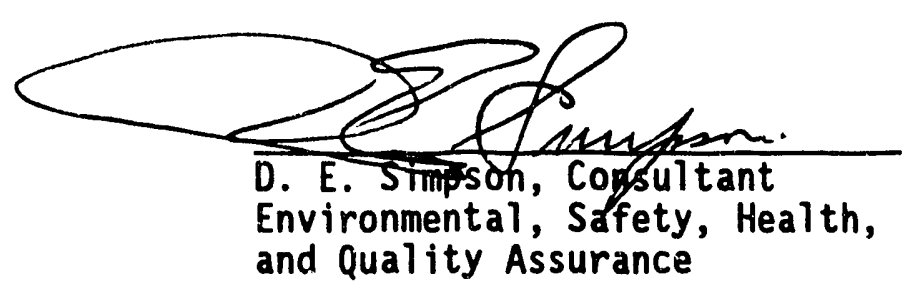

P.TAlleusum

R. T. Allemann, Staff Engineer Experimental Fluid Dynamics Pacific Northwest Laboratories.

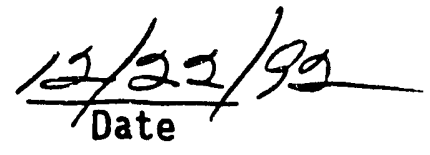

$\frac{12 / 29 / 92}{\text { Date }}$
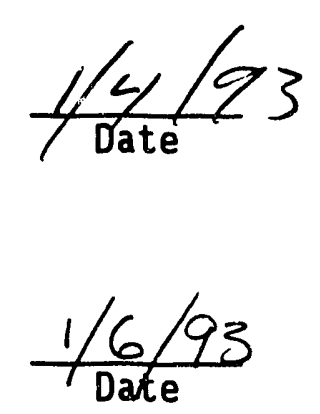

T. M. Burke, Principal Engineer Waste Characterization Analysis

Approved by:

G. D. Johnson, Program Manager $\frac{11 / 0 / 93}{\text { Date }}$

Work Completed:

June 1992 


\section{CONTENTS}

1.0 INTRODUCTION .................... 1 . . .

1.1 OVERVIEW ............................

1.2 BACKGROUND .......................

2.0 ANALYTICAL CONCEPTS/TANK 241-SY-101 CONTENTS . . . . . . . 2-1

2.1 ANALYTICAL CONCEPT ..................... 2-1

2.2 TANK 241-SY-101 CONTENTS .................. 2-1

3.0 ANALYSIS . . . . . . . . . . . . . . . 3-1

3.1 GAS GENERATION ....................... 3-1

3.2 GAS ACCUMULATION .................. 3-6

3.2.1 Gas Accumulation in the crust ...... 3-6

3.2.2 Gas Accumulation in the Convective Liquid Layer . . . 3-6

3.2.3 Gas Accumulation in the Slurry Layer ....... 3-7

3.2.4 Comparative Estimate of Gas Accumulation Volume . . . 3-12

3.3 GAS RELEASE ................ . . . . . . 12

3.4 UNCERTAINTY ASSESSMENT . . . . . . . . . . . . 3-16

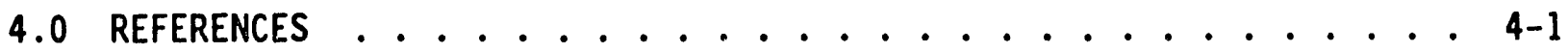
APPENDIXES

A GAS RELEASE EVENT VERTICAL TEMPERATURE PROFILES:

OCTOBER 1990 AND DECEMBER $1991 \ldots \ldots \ldots$. . . . . . . . A-1

B PHYSICAL PROPERTIES OF "WINDOW C" CORE SAMPLES ........ B-1

C GAS RELEASE PHENOMENON: TANK 241-SY-101 .......... C-1

D PHYSICAL MECHANISMS CONTRIBUTING TO THE EPISODIC GAS

RELEASE FROM HANFORD TANK $241-S Y-101 \ldots \ldots$. . . . . . D-1 
WHC-EP-0576

\section{LIST OF FIGURES}

1-1 Tank 241-SY-101 Surface Level Readings . . . . . . . . . . . 1-2

1-2 Distribution of Material in Tank 241-SY-101 . . . . . . . . . . . 1-4

3-1 Tank 241-SY-101 Surface Levels . . . . . . . . . . . . . . 3-2

3-2 Tank 241-SY-101 Surface Level Rise Rate. . . . . . . . . . . . 3-3

3-3 Tank 241-SY-101 Growth Rate Since June 27, 1981 . . . . . . . . . . 3-4

3-4 Neutrally Buoyant Void vs. Solid Packing: Tank 241-SY-101

Slurry Layer .. . . . . . . . . . . . . . . . 3-9

\section{LIST OF TABLES}

2-1 Tank 241-SY-101 Contents Data (Pre-GRE) . . . . . . . . . . 2-3

3-1 Summary of Slurry Layer Gas Accumulation Calculations . . . . . . 3-12

3-2 Minimum Gas Release and Maximum Retention . . . . . . . . . . 3-15

3-3 Gas Inventory Summary . . . . . . . . . . . . . . . . 3-16 
WHC-EP-0576

\section{ASSESSMENT OF GAS ACCUMULATION AND \\ RETENTION - TANK 241-SY-101}

\subsection{INTRODUCTION}

\subsection{OVERVIEW}

An approximate analysis has been carried out to assess and estimate the maximum quantity of gas that is likely to be accumulated within waste tank 241-SY-101, and the maximum quantity which is likely to be retained after gas release events (GRE).

According to the phenomenological models used for this assessment, based on interpretation of current and recent operational data, the estimated gas generation rate in the tank is approximately $4 \mathrm{~m}^{3} /$ day $\left(147 \mathrm{ft}^{3} /\right.$ day $)$. About half of this gas is released as it is generated, which is (essentially) continuously. The remainder is accumulated within the slurry layer of settled solids at the bottom of the tank, and released episodically in GREs, known as "burps," that are induced by unstable buoyant conditions which develop when sufficient gas accumulates in the slurry.

Calculations based on gas volumes to cause neutral buoyancy in the slurry predict the following:

- The maximum gas accumulation (at 1 atm pressure) that can occur without triggering a GRE is in the range of 606 to $1,039 \mathrm{~m}^{3}(21,400$ to $36,700 \mathrm{ft}^{3}$ )

- The maximum gas retention immediately after a GRE is equal to the maximum accumulation minus the gas released in the GRE.

GREs do not necessarily involve all of the slurry. In the largest GREs, which are assumed to involve all of the slurry, the minimum gas release (at 1 atm pressure) is calculated to be in the range of 193 to $328 \mathrm{~m}^{3}(6,800$ to $\left.11,600 \mathrm{ft}^{3}\right)$. The corresponding maximum gas retention would be 413 to $711 \mathrm{~m}^{3}$ $\left(14,600\right.$ to $\left.25,100 \mathrm{ft}^{3}\right)$.

\subsection{BACKGROUND}

Waste Tank 101-SY was first put into service in 1977, with the introduction of evaporator-concentrated waste known as "double shell slurry." Volumetric growth of this waste was noted almost immediately (Honeyman and Solbakken 1978). Complexant concentrate waste and additional double shell slurry were subsequently added. The tank reached its fully filled condition in 1980, with "slurry growth" continuing to be observed (Reynolds 1981). The tank settled into a pattern of steady volume increase, noted as surface level rise, and episodic gas release (Babad et al. 1992). The history of the surface level measurement is shown in Figure 1-1 (Burke et al. 1991). 
Figure 1-1. Tank 241-SY-101 Surface Level Readings.

\section{Tank 101-SY Surface Level Readings}

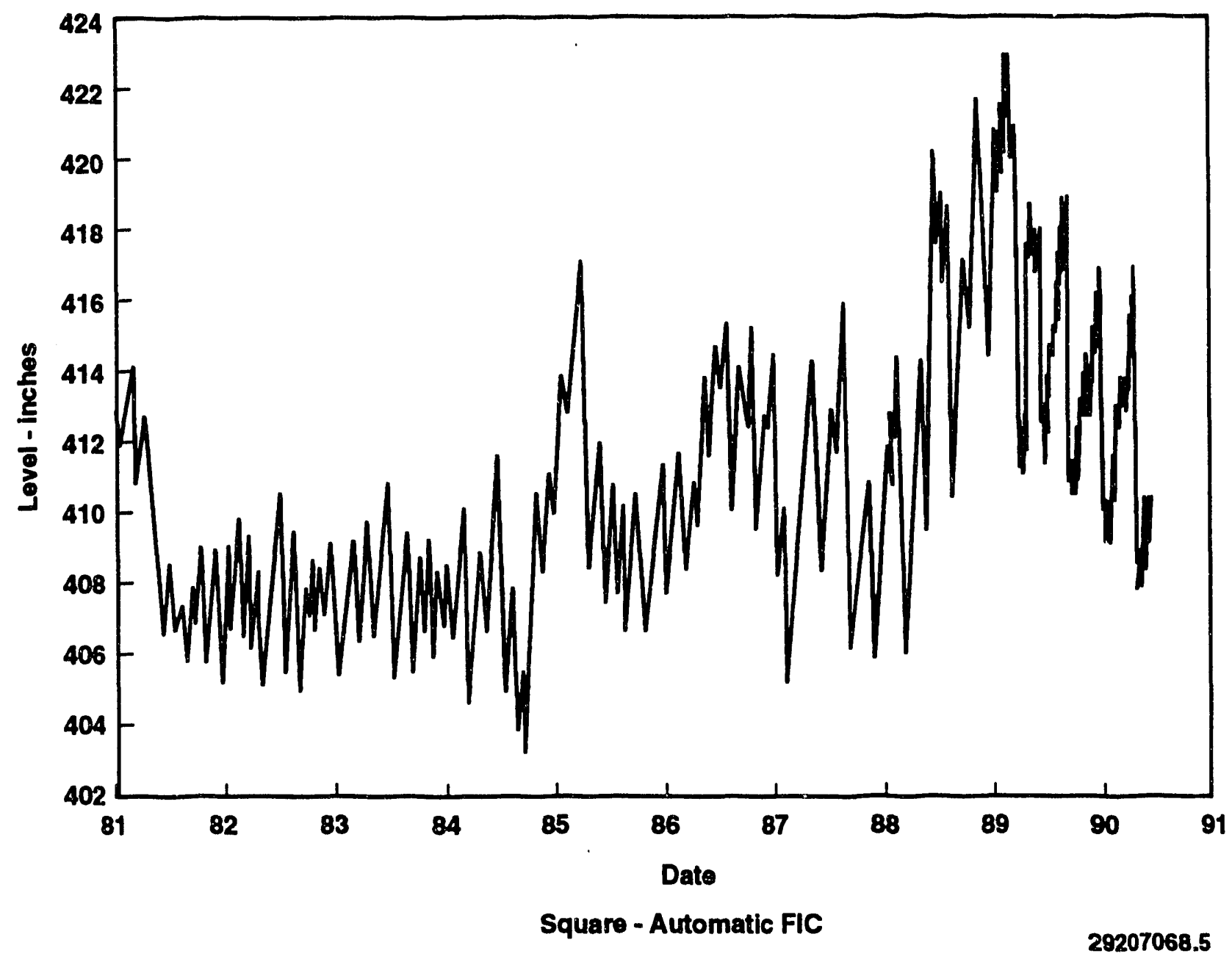


Concern for this behavior was heightened in 1989 , when it was recognized that the gases generated and released included a mixture of hydrogen (a fuel) and nitrous oxide (an oxidizer) that was flammable and potentially explosive even if not mixed with air. This condition had not been considered in the applicable Safety Analysis Report (Koontz 1986).

The gas mixture, known as "slurry growth gas," consists primarily of hydrogen $\left(\mathrm{H}_{2}\right)$, nitrous-oxide $\left(\mathrm{N}_{2} \mathrm{O}\right)$, and nitrogen $\left(\mathrm{N}_{2}\right)$, with smaller quantities of ammonia $\left(\mathrm{NH}_{3}\right)$ and water vapor $\left(\mathrm{H}_{2} \mathrm{O}\right)$, plus traces of other gases. This mixture is produced by radiolys is and radiation-induced chemical reactions involving organic materials and inorganic salts in the wastes (Meisel et al. 1992). The energetics of the reaction, and the total chemical heat generation in the tank, are not well known relative to the ${ }^{139} \mathrm{Cs}$ and ${ }^{90} \mathrm{Sr}$ heat generation, which is estimated to be about $40,000 \mathrm{BTU} / \mathrm{h}$, or about $12 \mathrm{~kW}$ (Reynolds 1992).

Direct sampling of the 101-SY contents has confirmed indirect evidence, from the vertical temperature profile in the tank, that the waste in 101-SY, between GRES, is located in several physical layers (Reynolds 1992), as illustrated in Figure 1-2. These layers are as follows:

- An upper layer, known as the "crust," which contains a large fraction of solids, but is obviously of low enough density to float, and which has thermal insulating properties relative to the liquid layer beneath

- A convective liquid layer, of nearly uniform temperature

- A thick, non-convective, layer of liquid and settled solid particles, known as the "slurry" layer. This layer may contain a sub-layer of denser and more viscous material, known as "sludge," at the bottom of the tank.

The episodic gas release behavior is consistent with the following phenomenology:

a. Gases generated in the slurry are retained and accumulate in the slurry, causing a tank content volume increase ard a reduction in the density of the slurry layer. The volume increase is apparent as a rising surface level of the tank contents.

b. The density of the slurry, or parts of it, becomes less than the density of the overlying liquid.

c. The unstable density relationship causes a "roll-over" of all (or a part) of the tank contents. The initial instability, triggering upward displacement of the slurry at some point, is augmented, once started, because of gas bubble expansion with the decreasing hydrostatic pressure at increasing elevations. 
Figure 1-2. Distribution of Material in Tank 241-SY-101.

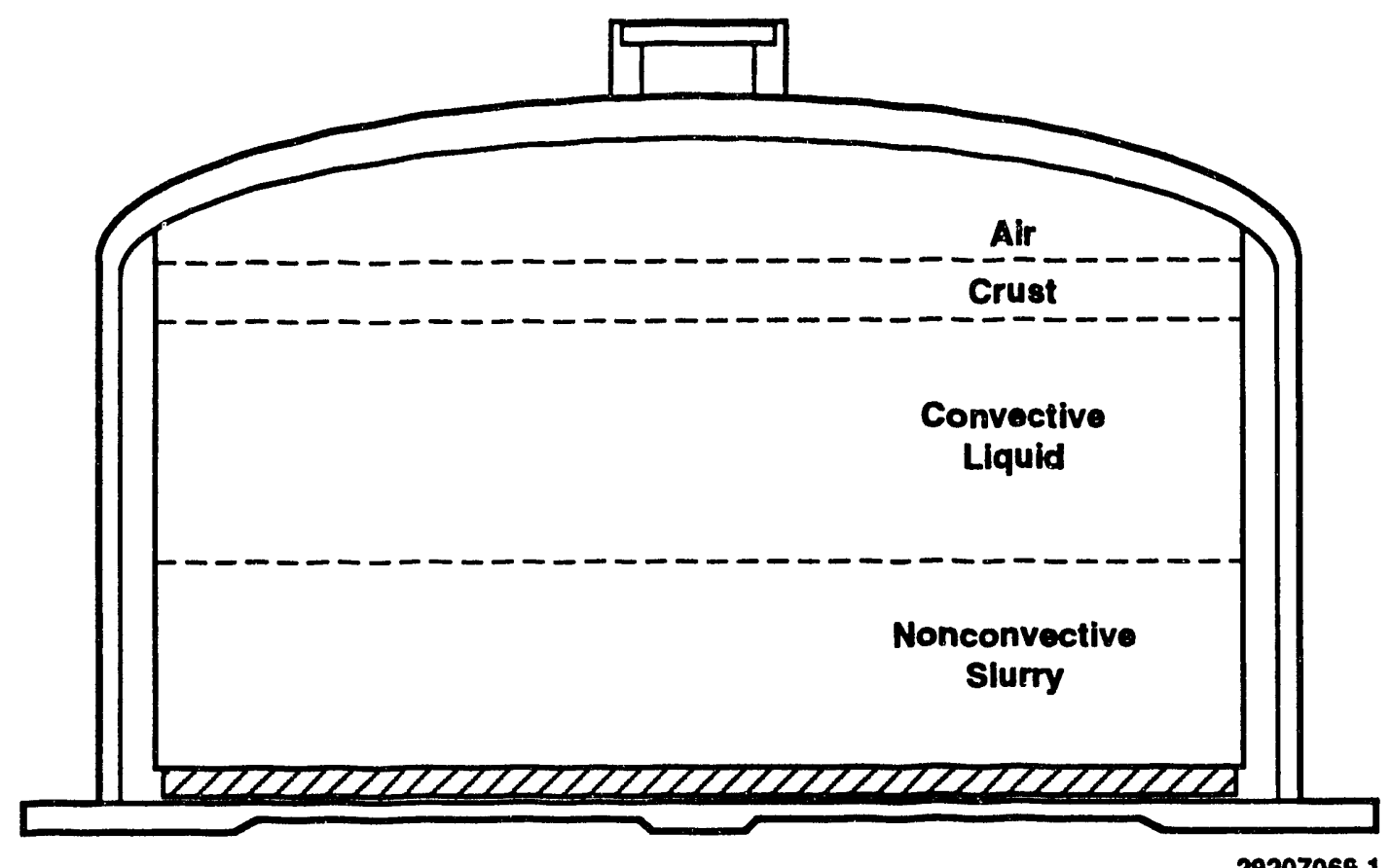

29207069.1 
d. The roll-over hydraulics carry liquid, gas, and solids from the slurry layer into the liquid layer and into or through the "crust." Bursts of slurry gas are released as slurry upwellings reach the surface.

e. After the initial upwellings, gases continue to evolve by "effervescence" through the liquid and crust.

f. Over a period of time, the heavier components of the slurry settle through the liquid, and the slurry layer is reformed. It appears that a large fraction of the slurry gas is retained in the slurry at this time. 
WHC-EP-0576

This page intentionally left blank. 
WHC-EP-0576

\subsection{ANALYTICAL CONCEPTS/TANK 241-SY-101 CONTENTS}

\subsection{ANALYTICAL CONCEPT}

In general, the accumulation (or storage) rate of gas in tank 241-SY-101 must equal the difference between the gas generation rate and the GRE as follows:

where

$$
\dot{Q}(\vec{r}, t)=\dot{G}(\vec{r}, t)-\dot{R}(\vec{r}, t)
$$

$$
\begin{aligned}
& \dot{Q}=\text { gas quantity accumulation rate per unit volume } \\
& G=\text { gas generation rate per unit volume } \\
& \dot{R}=\text { gas release rate, per unit volume }
\end{aligned}
$$

The parameters may, in concept, be variable in both space and time. The internal gas transport term has been omitted for simplicity.

For this analysis, the sas generation rate, $\dot{G}$, was assumed to be a constant in both space and time. The release rates in the crust and the convective liquid region were alsc assumed constant and equal to the generation rate, and the net transport between regions was assumed to be zero (that is, these regions were assumed $t_{n}$ be at equilibrium). The release rate from the slurry layer was assumed to be zero, between GRES, and to be a complex function of hydraulic rollover phenomenology when GREs occur.

The volume integrated release rate for the tank is the sum of the release term integrals for the three regions, and the integrated gas accumulation is the sum of the accumulation term integrals for the three regions. For this analysis, no attempt is made to perform the space-time dependent gas release analysis. This analysis requires a three component, three phase, three dimensional numerical analysis. The present assessment is 1 imited to evaluating equilibrium, or limiting conditions, in order to estimate the range of potential maximum gas accumulation before and after GREs.

\subsection{TANK 241-SY-101 CONTENTS}

The tank surface level and corresponding waste volume for this analysis were taken from conditions which existed shortly before the October 1990 gas release event (Barker et a1. 1991). The non-convect,ive slurry thickness at that time was estimated from the thermocouple (TC) data to be about 493 to $508 \mathrm{~cm}$ (194 to 200 in.). A similar estimate of $196 \mathrm{in}$. Was made from December 1991 TC data (Erhart 1992). Accordingly, a slurry layer thickness of 196 in. was used to represent the thickness just before a "maximum" GRE. It was assumed that the slurry was at the point of neutral buoyancy at that time, and the hydrostatic pressure in the slurry was calculated on that basis.

The crust thickness was estimated, very approximately, on the basis of thermal data, video observations, and sampling information, in addition to the primary observation that "it floats" (Reynolds 1992). Temperature data show a consistent temperature drop between the convective liquid temperature and the tank dome air temperature of some 1.1 to $10^{\circ} \mathrm{C}\left(30\right.$ to $\left.50{ }^{\circ} \mathrm{F}\right)$. The TCs are four feet apart, piacing an upper limit on the thickness. Thermal 
conductivity estimates are consistent with a layer thickness of "several feet." Core sampling experience indicates a layer thickness of 61 to $102 \mathrm{~cm}$ (24 to 40 in.). Video observations indicate that the layer is discontinuous and highly fluid in behavior. A layer thickness of $0.76 \mathrm{~m}(2.5 \mathrm{ft})$, and an average density (specific gravity) of 1.35 were selected. The density corresponds to about 17 percent gas volume, assuming that the volume fractions of liquid and centrifuged solids equivalent are equal. This density value and the gas volume value are uncertain, but seem consistent with available data and observations.

The convective liquid layer thickness, $472 \mathrm{~cm}$ (186 in.), is the remainder. The 1 iquid density used in the analysis is the "best" value, based on Window C measurements of supernatant liquid (Reynolds 1992).

Table 2-1 summarizes parameters relevant to component volumes and pressures in the tank.

Vertical temperature profiles before, during, and immediately after the October 1990 and December 1991 GREs are printed in Appendix A. Physical properties data obtained from "Window C" core samples of tank 101-SY are provided in Appendix B.

In this report specific gravity is generally used as density, without denoting the units. Unless noted otherwise, density, with no units given, is the specific gravity and is understood to be in the units of $\mathrm{gm} / \mathrm{mL}$, or $\mathrm{kg} / \mathrm{L}$. 
Table 2-1. Tank 241-SY-101 Contents Data (Pre-GRE).

\begin{tabular}{|l|c|c|c|c|c|}
\hline \multicolumn{1}{|c|}{ Layer } & Thickness & $\begin{array}{c}\text { Specific } \\
\text { gravity }\end{array}$ & $\Delta P$ (atm) & $\begin{array}{c}\text { P-ave. } \\
\text { (atm) }\end{array}$ & Volume \\
\hline "Crust" & $\begin{array}{c}76 \mathrm{~cm} \\
(30 \mathrm{in.})\end{array}$ & 1.35 & 0.10 & 1.05 & $\begin{array}{c}312 \mathrm{~m}^{3} \\
\left(11,000 \mathrm{ft}^{3}\right)\end{array}$ \\
\hline $\begin{array}{l}\text { Convective } \\
\text { liquid }\end{array}$ & $\begin{array}{c}472 \mathrm{~cm} \\
(186 \mathrm{in.})\end{array}$ & 1.46 & 0.67 & 1.44 & $\begin{array}{c}1,926 \mathrm{~m}^{3} \\
\left(68,000 \mathrm{ft}^{3}\right)\end{array}$ \\
\hline $\begin{array}{l}\text { Non-convective } \\
\text { slurry }\end{array}$ & $\begin{array}{c}498 \mathrm{~cm} \\
(196 \mathrm{in.})\end{array}$ & $1.46 *$ & 0.70 & 2.12 & $\begin{array}{c}2,039 \mathrm{~m}^{3} \\
\left(72,000 \mathrm{ft}^{3}\right)\end{array}$ \\
\hline Total & $\begin{array}{c}1,046 \mathrm{~cm} \\
(412 \mathrm{in.})\end{array}$ & $\mathrm{N} / \mathrm{A}$ & 1.47 & $\mathrm{~N} / \mathrm{A}$ & $\begin{array}{c}4,304 \mathrm{~m}^{3} \\
\left(152,000 \mathrm{ft}^{3}\right)\end{array}$ \\
\hline
\end{tabular}

*Assumed to be at the neutrally buoyant condition. GRE = Gas release events. 
WHC-EP-0576

This page intentionally left blank. 


\subsection{ANALYSIS}

\subsection{GAS GENERATION}

The gas generation rate is inferred from tank 241-SY-101 operational data. Laboratory and theoretical data indicate that radiolysis, plus chemical reactions, can account for the gas quantities which appear to be produced (Meisel et al. 1992). However, at this time, these data do not account for the relative quantities of the gas constituents, and they are not sufficient to indicate quantitative differences between the various waste layers in the tank. Laboratory data show temperature sensitivity of relevant chemical reactions, as well as radiation sensitivity, but this laboratory data are not at this time correlated to operational data.

Operational data, as well, provide no basis on which to differentiate gas generation in the various waste layers, nor to distinguish time or temperature dependence. Accordingly, the analytical model used for the gas generation term is as follows:

$$
\dot{G}=\text { constant, in both space and time }
$$

The use of a constant value for the gas generation rate, without functional dependence on temperature, radiation level, or waste constituents or physical states, does not mean that such dependencies do not exist. Current operational, laboratory, and theoretical data do not establish values for such dependencies; however, if future operations or mitigation programs cause large changes in waste parameters, significant changes in gas generation rates could occur. For example, an increased temperature could cause an increased gas generation rate.

The reference value for $\dot{G}$ is calculated from recent operational data, (i.e., the time period 1989-1992). The calculation is dependent on assumptions regarding the gas retention term, which will be discussed later. The assumptions are as follows:

- Gas release from the convective liquid and crust layers equals gas generation, in the time period between GREs

- Gas release from the slurry is zero in these time periods.

The measured surface level record since January 1989 is shown in Figure 3-1. The average level growth rate measured by the FIC during the periods of consistent level increase is found graphically to be approximately $0.23 \mathrm{~cm} /$ day ( $0.09 \mathrm{in}$./day). Figure 3-2 shows an integration (by Reynolds) of the positive surface level growth, in which level drops of over $1.3 \mathrm{~cm}$ $(0.5 \mathrm{in.})$ have been deleted.

Figure 3-3 shows a weekly average surface growth rate for nearly the entire 241-SY-101 operating period. Again, sudden surface level reductions were deleted. Neglecting the time period of about 2,300 to 3,000 days, influenced by "air lancing events," the growth is seen to have been about 0.25 to $0.28 \mathrm{~cm} /$ day $(0.10$ to $0.11 \mathrm{in} . /$ day $)$ for most of the prior history, but appears to have declined to about $0.23 \mathrm{~cm} /$ day $(0.09 \mathrm{in} . /$ day) currently. 
WHC-EP-0576

Figure 3-1. Tank 241-SY-101 Surface Levels.

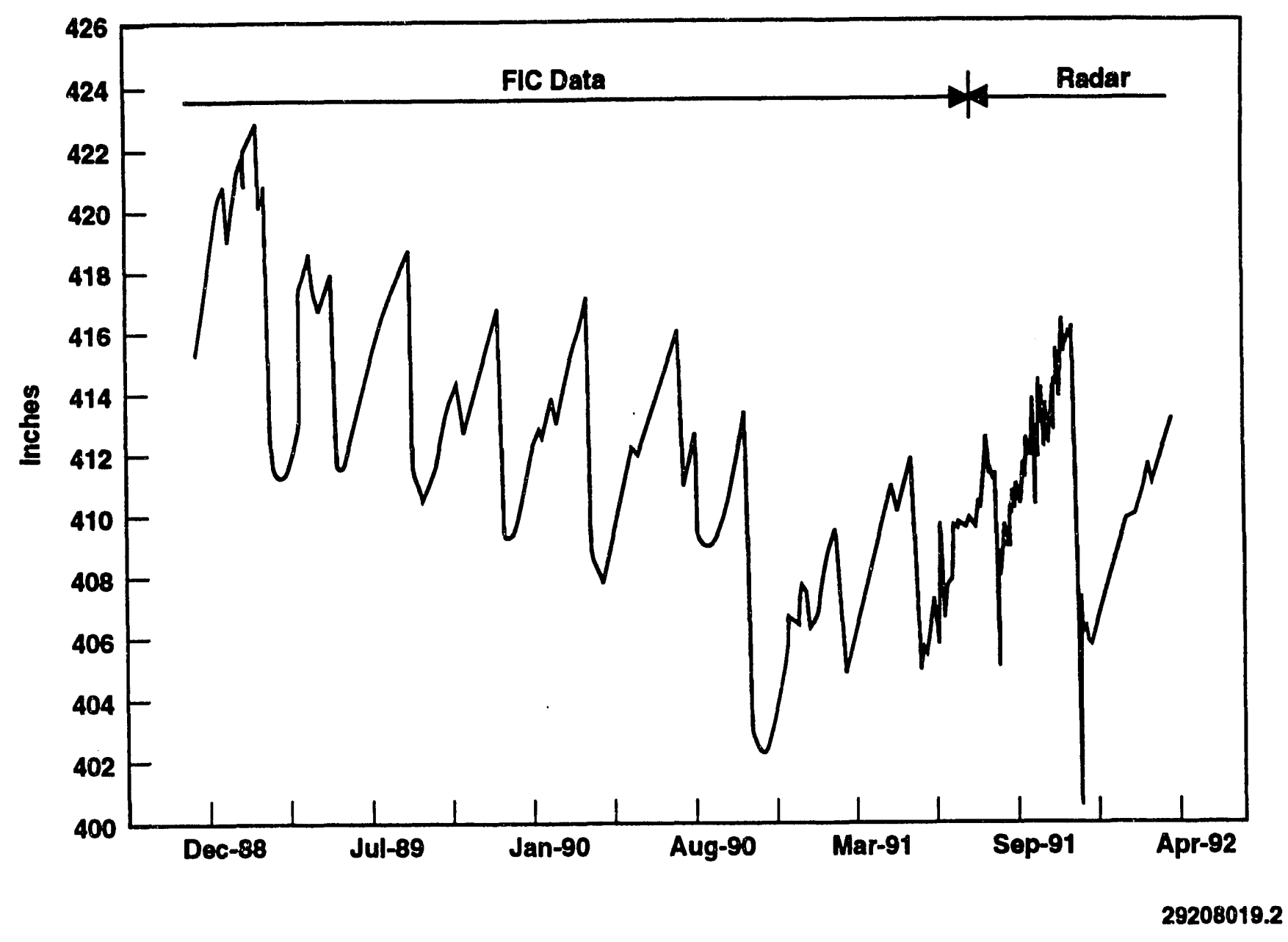


WHC-EP-0576

Figure 3-2. Tank 241-SY-101 Surface Level Rise Rate.

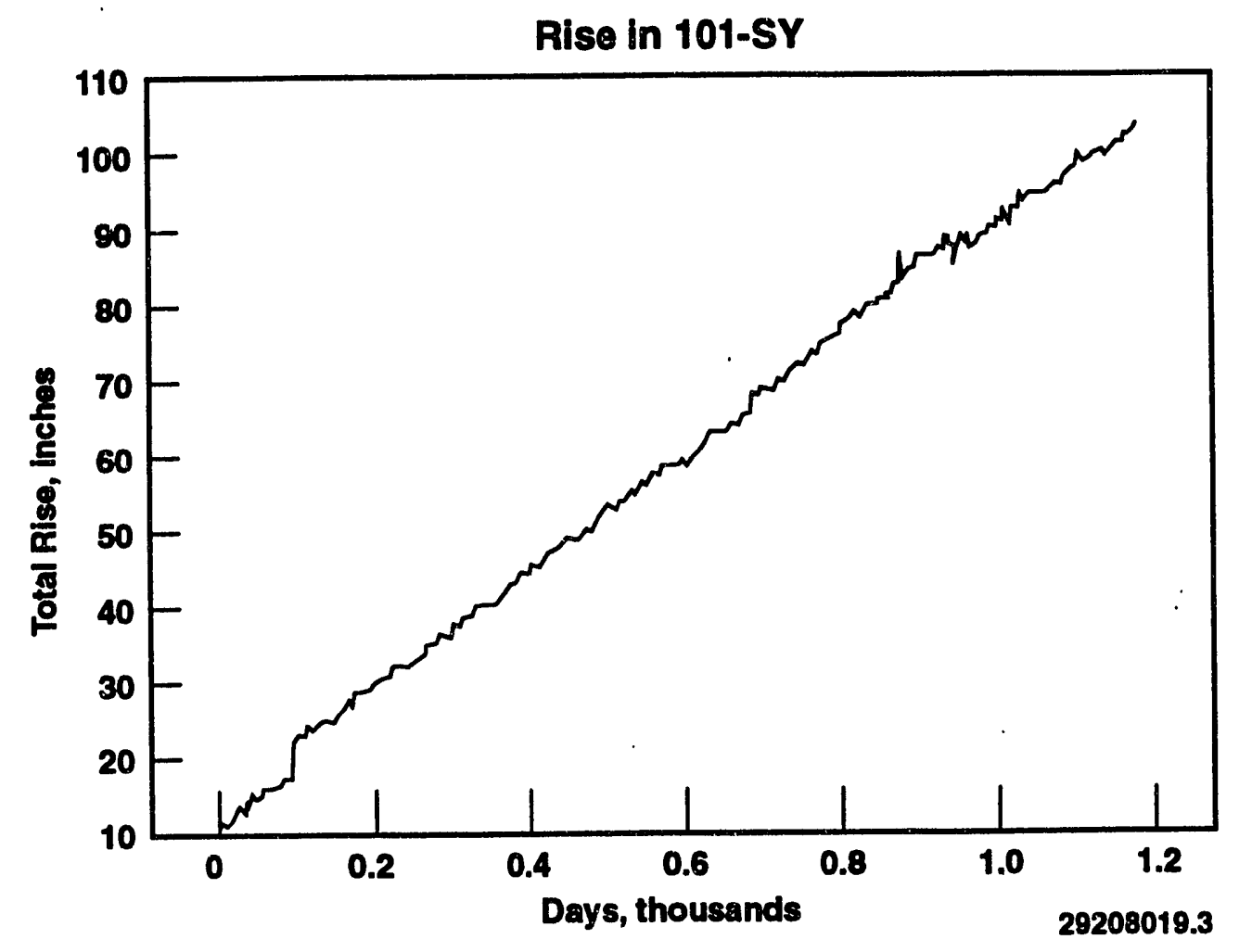


WHC-EP-0576

Figure 3-3. Tank 241-SY-101 Growth Rate Since June 27, 1981.

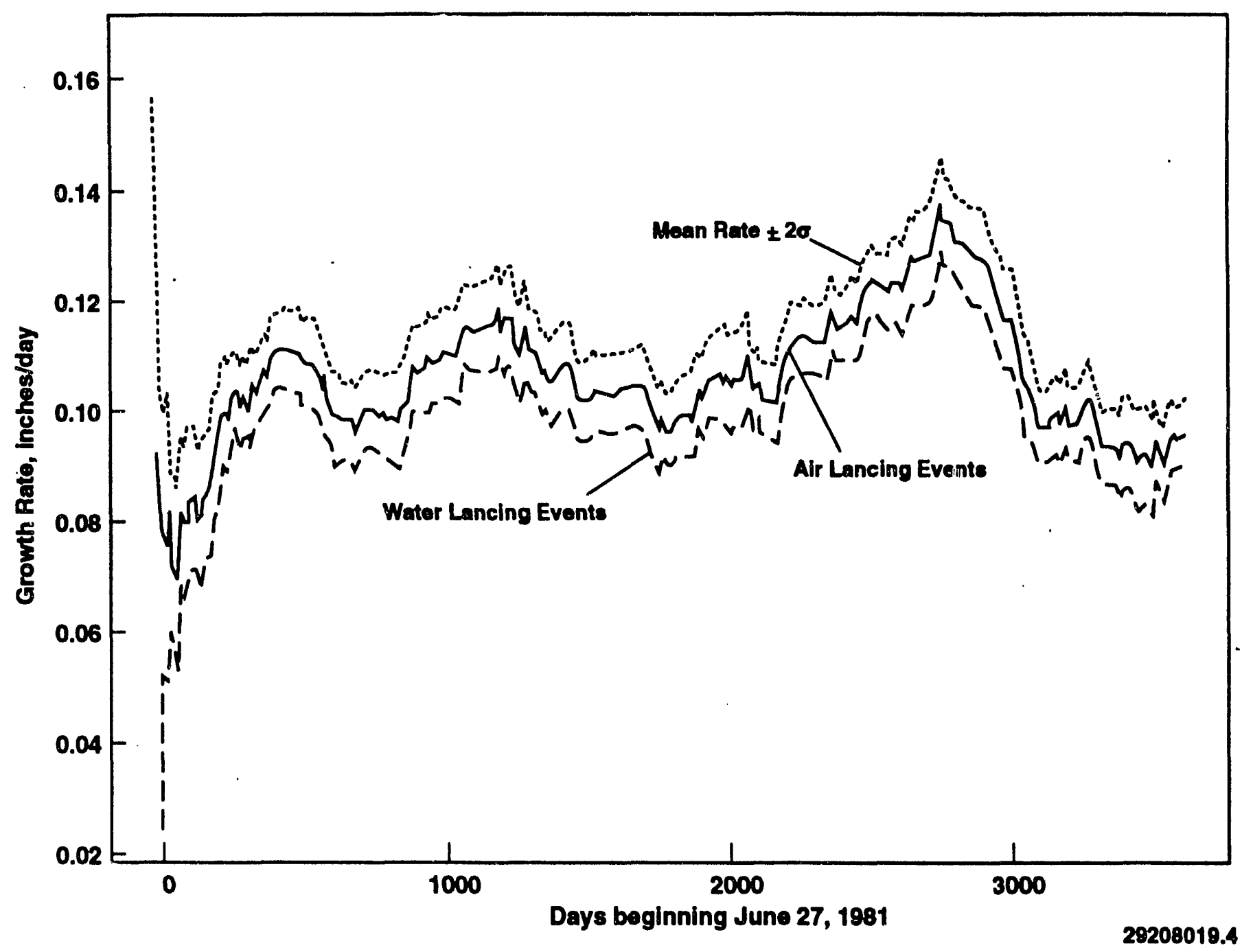


A surface level growth rate of $0.23 \mathrm{~cm} /$ day $(0.09 \mathrm{in} . /$ day) equates to a waste volume increase rate of $0.94 \mathrm{~m}^{3} /$ day $\left(33.1 \mathrm{ft}^{3} /\right.$ day). If all of this growth is due to gas accumulation in the slurry layer, at an average pressure of $2.12 \mathrm{~atm}$, this corresponds to a gas accumulation rate, which equals the generation rate, of $2 \mathrm{~m}^{3}\left(70 \mathrm{ft}^{3}\right)$ (gas at 1 atm pressure).

NOTE: The temperature correction is neglected*.

The corresponding volumetric gas generation rate is as follows:

$$
\begin{aligned}
G= & \frac{70}{72,000} \quad \frac{\mathrm{m}^{3}(\text { gas at } 1 \text { atm) } / \text { day }}{\mathrm{m}^{3} \text { (waste) }} \\
& =0.97 \times 10^{-3} \frac{\mathrm{m}^{3}(\text { gas } 1 \text { atm) } / \text { day }}{\mathrm{m}^{3} \text { (waste) }}
\end{aligned}
$$

The calculated total gas generation rate, then, is as follows:

$$
\left(0.97 \times 10^{-3}\right) \times 4.300 \mathrm{~m}^{3}=4.16 \mathrm{~m}^{3}(\text { gas } 1 \mathrm{~atm}) / \text { day }
$$

According to our model then:

- $2 \mathrm{~m}^{3} /$ day $\left(70 \mathrm{ft}^{3} /\right.$ day $) \times 365 \mathrm{~d}=725 \mathrm{~m}^{3}\left(25,600 \mathrm{ft}^{3}\right)=$ annual gas generation in the slurry released during GREs.

- $2.2 \mathrm{~m}^{3} /$ day $\left(77 \mathrm{ft}^{3} /\right.$ day $)=$ continuous release from the waste surface. (This gas would appear at a concentration of $89 \mathrm{ppm}$ in a ventilation flow of $17 \mathrm{~m}^{3} / \mathrm{min}\left(600 \mathrm{ft}^{3} / \mathrm{min}\right)$; if 36 percent of the gas is $\mathrm{H}_{2}$, a $\mathrm{H}_{2}$ concentration of $32 \mathrm{ppm}$ is calculated.)

Reported estimates of GRE gas releases from April 1990 through August 1991 are a minimum of $765 \mathrm{~m}^{3}\left(27,000 \mathrm{ft}^{3}\right)$ to a maximum of $1,019 \mathrm{~m}^{3}\left(36,000 \mathrm{ft}^{3}\right)$ (Babad et al. 1992). Adding $255 \mathrm{~m}^{3}$ to $340 \mathrm{~m}^{3}\left(9,000 \mathrm{ft}^{3}\right.$ to $\left.12,000 \mathrm{ft}^{3}\right)$ for the December 1991 event gives a 2-year total of $1,019 \mathrm{~m}^{3}$ to $1,359 \mathrm{~m}^{3}\left(36,000 \mathrm{ft}^{3}\right.$ to $\left.48,000 \mathrm{ft}^{3}\right)$, or an annual GRE release of $510 \mathrm{~m}^{3}$ to $680 \mathrm{~m}^{3}\left(18,000 \mathrm{ft}^{3}\right.$ to $24,000 \mathrm{ft}^{3}$ ), in reasonable agreement with the model estimate.

Recent $\mathrm{H}_{2}$ concentrations in the 101-SY ventilation, measured by new "MOS" instrumentation, are typically in the range 25-35 ppm.

* Gas generated and accumulated in the slurry layer is at an average temperature of 49 to $54{ }^{\circ} \mathrm{C}\left(120\right.$ to $\left.130{ }^{\circ} \mathrm{F}\right)$. Correction to the tank dome air space temperature would be a volume reduction of about 5 percent; correction to Standard Temperature and Pressure would be a reduction of about 15 percent. 


\subsection{GAS ACCUMULATION}

Because the gas release rate in the crust and in the convective liquid is assumed to equal the gas generation rate, it is of interest to estimate the probable maximum equilibrium accumulation of gas in these regions.

This analysis also uses a model to estimate gas release from the slurry on the basis of postulating limiting conditions of gas accumulation;

therefore, a gas accumulation estimate precedes a gas release estimate.

\subsubsection{Gas Accumulation in the Crust}

Observations regarding crust characteristics are described in Section 2.0. A nominal crust density of 1.35 ("it floats"), together with a rather arbitrary assignment of equal parts "centrifuged solids" equivalent $(\rho=1.8)$ and supernatant liquid $(\rho=1.46)$, results in a gas void volume fraction of 0.17 . This gas volume is approximately $57 \mathrm{~m}^{3}\left(2,000 \mathrm{ft}^{3}\right)$, in situ and at $1 \mathrm{~atm}$; the corresponding surface level increase is about $13 \mathrm{~cm}$ (5 in.).

\subsubsection{Gas Accumulation in the Convective Liquid Layer}

A typical method for calculating the gas inventory in a liquid with internal gas generation would be based on gas bubble size and bubble vertical rise time. Bubble sizes are not calculated, nor are bubble size measurements. However, the retained gas volume is estimated to be negligible, based on the rise time of an arbitrary small bubble. For example, the bubble terminal velocity is calculated from the Stokes equation:

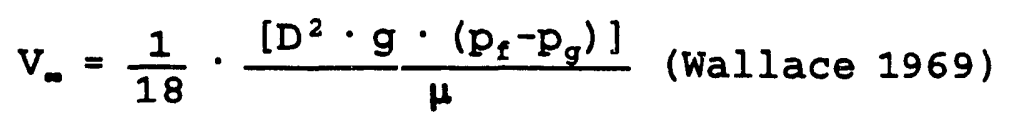

where

$$
\begin{aligned}
& g=\text { gravity } \\
& D=\text { bubble diameter } \\
& \rho_{f}=1 \text { iquid density } \\
& \rho_{g}=\text { gas density } \\
& \mu^{\prime}=\text { liquid viscosity }
\end{aligned}
$$

For a $0.1 \mathrm{~mm}$ bubble, $D=3 \times 10^{-4} \mathrm{ft}$. Using $\rho_{\mathrm{f}}=90 \mathrm{lb} / \mathrm{ft}^{3}$,

$$
\rho_{g}=0 \text {, and } \mu=30 c P=6 \times 10^{-4} \frac{1 b-s e c}{f t^{2}} \text {, }
$$

the velocity is $V_{\infty}=8 \times 10^{-4} \mathrm{ft} / \mathrm{sec}=65 \mathrm{ft} /$ day $(20 \mathrm{~m} / \mathrm{day})$ 
The average travel distance through the convective layer is $236 \mathrm{~cm}=2.4 \mathrm{~m}$ (93 in. $=7.75 \mathrm{ft}$ ). The average travel time is 0.12 days, and the corresponding gas hold-up is about $0.23 \mathrm{~m}^{3}$ ( $8 \mathrm{ft}^{3}$ ) (which is negligible).

A more significant gas retention mechanism in the convective liquid may be the adherence of gas bubbles to solid particles. Observations have been reported where there are solids that do not seem to settle out over long periods. Measured solid fractions from core samples (Window C) indicated an average weight fraction of about 16 percent solids, and about 12 percent near the top of the layer (Reynolds 1992). This upper material, of 12 weight percent solids, is about 10 volume percent solids. Tingey reported 7 volume percent ( 9 weight percent) solids in the convective liquid. Assuming that the solids do not settle out because of adherent voids, an upper limit of gas accumulation in the convective liquid can be estimated. The volume fraction of gas voids to provide neutrai buoyancy for 7-10 volume percent solids (the "solids" density in this case is the density of the "centrifuged solids" portion of the core sample, about 1,8 ) is about 2 volume percent. This corresponds to somewhat more than $28 \mathrm{~m}^{3}\left(1,000 \mathrm{ft}^{3}\right)$ at the average pressure of $1.44 \mathrm{~atm}$, and roughly $57 \mathrm{~m}^{3}\left(2,000 \mathrm{ft}^{3}\right)$ gas at $1 \mathrm{~atm}$. The equivalent surface

level increase is about $7.6 \mathrm{~cm}$ ( 3 in.).

\subsubsection{Gas Accumulation in the Slurry Layer}

The slurry gas release function is physically complex. Detailed multicomponent, multi-phase, three dimensional models are required to compute this behavior (Allemann et al. 1991). Uncertainties in physical properties are significant to the calculated results, and sensitivity studies are necessary to assess the importance of key uncertainties.

A simplified model for $\dot{R}_{s}$ is used in the following analysis, to estimate the maximum quantity of gas that could accumulate in the slurry, and the maximum amount which could be retained following a GRE.

The slurry is represented by its average properties and state conditions. It is assumed that the gas can accumulate in the slurry until the gas concentration is such that the mixture density equals the density of the convective liquid.

Non-uniform gas distribution is actually to be expected as potentially contributing to variations in individual GRE magnitudes (see, for example: Alleman 1992). The total gas quantity required to produce neutral buoyancy of the entire slurry layer is only slightly sensitive to such variations in gas distribution.

This model assumes that any cohesive stress tending to hold the slurry to the bottom of the tank is negligible. If there were a cohesive stress of 0.3 psi (typical of measured shear stress of slurry core samples at $50{ }^{\circ} \mathrm{C}$ ), an additional positive buoyancy force of $86,638 \mathrm{~kg}(191,000 \mathrm{lb})$ would be required for roll-over of 100 percent of the slurry. This would correspond to an additiona] gas volume of about $57 \mathrm{~m}^{3}\left(2,000 \mathrm{ft}^{3}\right)$ in situ, about $113 \mathrm{~m}^{3}$ $\left(4,000 \mathrm{ft}^{3}\right)$ at $1 \mathrm{~atm}$ (which is not included in the following assessment of potential gas accumulation). 
The slurry is a three-component mixture. The gas concentration in the mixture that is required to produce neutral buoyancy is dependent on the concentrations and densities of the liquid and solid components. Neutral buoyancy is defined as that mixture density that equals the density of the supernatant fluid, (i.e., the convective liquid).

In general

$$
\rho_{m}=\sum_{f} f_{f} \rho_{f}
$$

where

$\rho_{\text {. }}=$ mixture density

$\rho_{i}=$ component density of component "q"

$f_{\mathfrak{l}}=$ volume fraction of component " $q$ "

Assuming that gas accumulation displaces the other components equally, the solid fraction and liquid fraction may be taken as mutually dependent, and the gas fraction for neutral buoyancy can be calculated as a function of either the solid or liquid fraction.

Define:

$f_{s, 0}=$ solid fraction at zero gas content

$f_{1,0}^{s, 0}=$ liquid fraction at zero gas content

then, by definition:

$$
f_{s, 0}+f_{l, 0}=1
$$

Defining:

$\propto=f_{g}=$ gas (void) fraction

then, the three-component mixture density is as follows:

$$
\rho_{m}=[1-\propto]\left[f_{s, 0} \rho_{s}+\left(1-f_{s, 0}\right) \rho_{l}\right]
$$

Figure 3-4 is the graph of $\propto$ (gas void fraction) vs. $f_{s, 0}$, the numerator of the solid/liquid ratio, $f_{s, 0} / f_{l, 0}$, for the density parametérs:

$$
\begin{aligned}
& \rho_{m}=1.46 \\
& \rho_{s}=2.18 \\
& \rho_{1}=1.46
\end{aligned}
$$


Figure 3-4. Neutrally Buoyant Void vs. Solid Packing: Tank 241-SY-101 Slurry Layer.

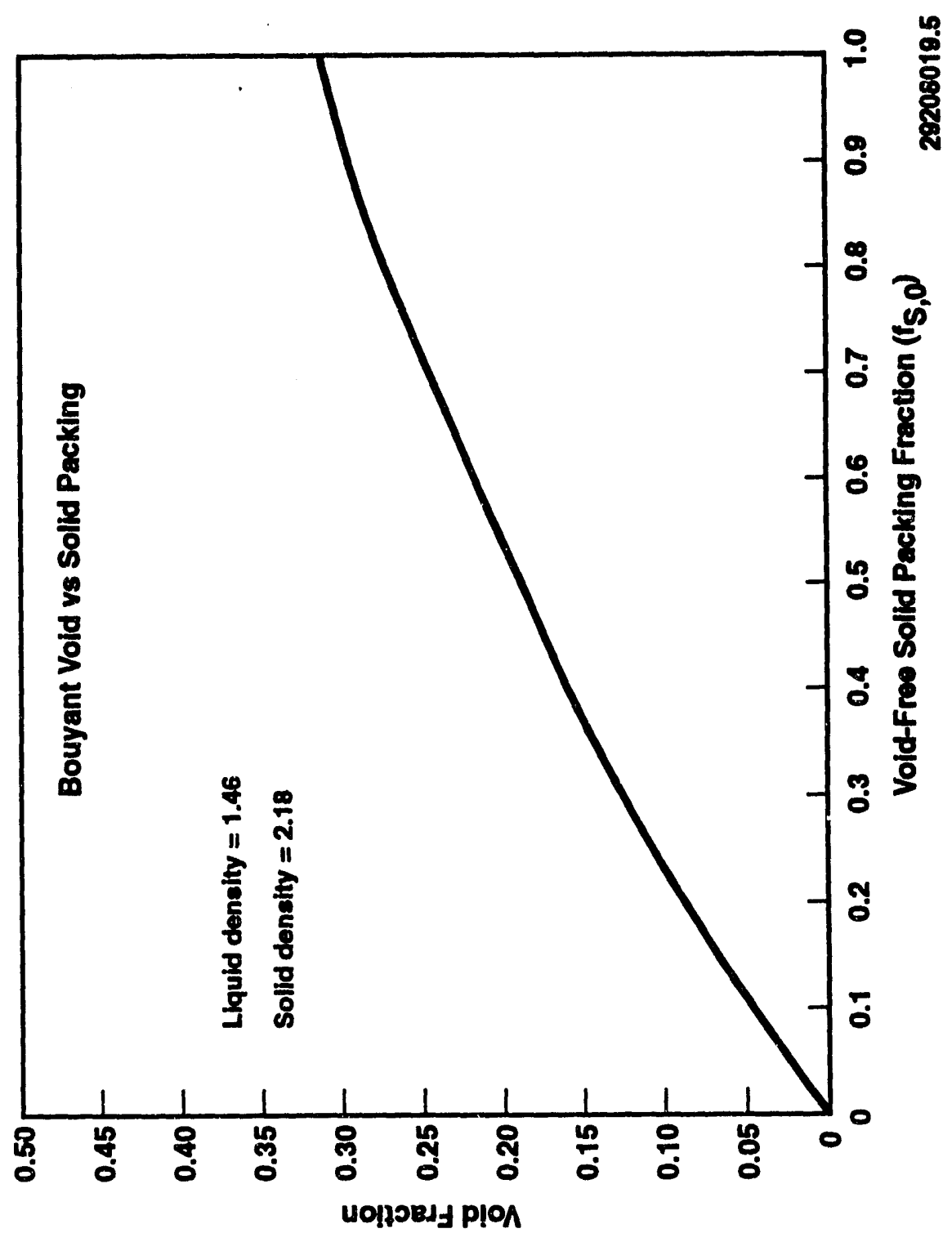


The liquid density value of 1.46 is the best value for the supernatant liquid based on "Window C" sample characterization data (Reynolds 1992). The solid density value (2.18) is the average of the densities of $\mathrm{NaNO}_{3}(2.26)$ and $\mathrm{NaNO}_{2}$ (2.1).

Substantial characterization has been done on material samples from 101-SY (Herting et a1. 1992; Reynolds 1992). No direct measurements exist, however, for several of the key parameters for this analysis, particularly:

- The slurry solid/liquid ratio

- Gas void content

- Density of the solid component.

These parameters then must be assumed, inferred, or deduced from the available experimental data, observations, and the background body of knowledge.

The most direct interpretation of available data has been selected as our base case, and alternate interpretations have been applied for comparison.

3.2.3.1 Gas Accumulation in the S1urry Layer: Base Case. Centrifuging of tank 241-SY-101 core samples compacted the so-called "centrifuged solids" to an average density of 1.8 . For the base case, this representative value is taken for the compaction of the slurry in tank 241-SY-101. Any gas content remaining after sample preparation and centrifuging is assumed to be negligible, either because the gas quantity is virtually zero or any retained gas is so tightly held that it would not be subject to episodic release.

Using the selected solids density of $2.18 \mathrm{~g} / \mathrm{mL}$, the solid and liquid fraction of the "centrifuged solids" are calculated as follows:

$$
\begin{gathered}
\left(f_{s, 0} \times 2.18\right)+\left(1-f_{s, 0}\right)(1.46)=1.8 \\
f_{s, 0}=\frac{1.8-1.46}{2.18-1.46}=\frac{0.34}{0.72}=0.47
\end{gathered}
$$

then

$f_{1,0}=0.53$

The gas void content to bring this solid/liquid mixture to neutral buoyancy, $\propto_{b}$, is as follows:

$$
\propto_{b}=\frac{1.8-1.46}{1.8}=0.19
$$

The corresponding calculated neutrally buoyant gas accumulation in the slurry layer is

$$
(0.19)(72,000)=388 \mathrm{~m}^{3}\left(13,700 \mathrm{ft}^{3}\right) \text { in situ }
$$

This would produce a $0.94 \mathrm{~m}$ (37 in.) surface level increase. 
Converting to atmospheric pressure (and neglecting temperature change): Buoyant gas content $=321 \mathrm{~m}^{3}\left(29,000 \mathrm{ft}^{3}\right)$ (gas at $1 \mathrm{~atm}$ )

This calculation did not make use of the measured density of bulk samples of the non-convective slurry; the "best" value from these measurements was 1.69 (Reynolds 1992). The difference between 1.8 and 1.69 is interpreted as a difference in solid/liquid ratio. Centrifuging of slurry layer samples compacted the "centrifuged solids" to an average of 75 percent of the sample volume. Since the true solids volume was unchanged, the volume fraction in the buik sample was 0.75 times the volume fraction in the centrifuged solids:

$$
(0.75)(0.47)=0.35
$$

The calculated buik density with this solid fraction, with negligible voids is

$$
\rho_{\mathrm{m}}=(0.35)(2.18)+(0.65)(1.46)=1.71 \mathrm{~g} / \mathrm{m} !
$$

which is close to the measured value, 1.69 .

3.2.3.2 Gas Accumulation in the Slurry Layer: Alternate Case 1. The base case assumes negligible gas content in the "centrifuged solids," but there are no experimental data which prove this assumption. An estimate of the potential gas content that could exist if the solids could be more tightly compacted can be made by assuming that the solid/liquid components of the slurry can be compacted to the consistency of clay; the solid volume fraction of clay is reported as 0.65 (refer to Table 3-1).

The density of a vcid free mixture of 65 percent solids and 35 percent liquid is $(0.65)(2.18)+(0.35)(1.46)=1.93$.

The gas void fraction to reduce the density to 1.8 would be 0.07 . The gas void fraction for neutral puoyancy is 0.24 . The corresponding neutral buoyancy gas quantity is $490 \mathrm{~m}^{3}\left(17,300 \mathrm{Ft}^{3}\right)$, in situ, and $1,039 \mathrm{~m}^{3}$ $\left(36,700 \mathrm{ft}^{3}\right)$ at 1 atm. This interpretation of the available information is considered to be conservative; that is, to be a probable over-estimate of potential gas accumulation.

3.2.3.3 Gas Accumulation in the Slurry Layer: Alternate Case 2. It may be that the slurry compaction, in situ, is not as great as the centrifuged compaction, and is betier represented by the buik core samples. If the samples are void-free, the solids fraction is about 0.35 , (as calculated above). The corresponding buoyant void fraction is 0.14 . The corresponding gas volume is $286 \mathrm{~m}^{3}\left(10,100 \mathrm{ft}^{3}\right)$, in situ, and $606 \mathrm{~m}^{3}\left(21,400 \mathrm{ft}^{3}\right)$ at $1 \mathrm{~atm}$.

The base case is dependent on the assumption that gas content in the "centrifuged solids" is negligible, as well as the assumed solid particle density of 2.18. Experimental verification or rejection of these assumptions is desirable. 
Table 3-1. Summary of STurry Layer Gas Accumulation Calculations.

\begin{tabular}{|l|c|c|c|}
\hline & Base case & Alternate case 1 & Alternate case 2 \\
\hline $\begin{array}{l}\text { Void-free } \\
\text { slurry } \\
\text { density g/mL }\end{array}$ & 1.8 & 1.93 & 1.7 \\
\hline $\begin{array}{l}\text { Solid/liquid } \\
\text { volume ratio }\end{array}$ & $.47 / .53$ & $.65 / .35$ & $.35 / .65$ \\
\hline $\begin{array}{l}\text { Buoyant void } \\
\text { fraction }\end{array}$ & 0.19 & 0.24 & 0.14 \\
\hline $\begin{array}{l}\text { Maximum gas, } \\
\text { in situ }\end{array}$ & $388 \mathrm{~m}^{3}\left(13,700 \mathrm{ft}^{3}\right)$ & $490 \mathrm{~m}^{3}\left(17,300 \mathrm{ft}^{3}\right)$ & $286 \mathrm{~m}^{3}\left(10,100 \mathrm{ft}^{3}\right)$ \\
\hline $\begin{array}{l}\text { Maximum gas, } \\
1 \text { atm }\end{array}$ & $821 \mathrm{~m}^{3}\left(29,000 \mathrm{ft}^{3}\right)$ & $1,039 \mathrm{~m}^{3}\left(36,700 \mathrm{ft}^{3}\right)$ & $606 \mathrm{~m}^{3}\left(21,400 \mathrm{ft}^{3}\right)$ \\
\hline
\end{tabular}

NOTE: These values do not include any estimate or allowance for positive buoyancy, beyond neutral buoyancy, due to cohesive shear strength of the slurry.

\subsubsection{Comparative Estimate of Gas Accumulation Volume}

An alternate estimate of the total gas volume in tank $241-5 Y-101$ can be made on the basis of a tank inventory balance. The measured tank level just prior to the October $1990 \mathrm{GRE}, 1,046 \mathrm{~cm}$ ( $412 \mathrm{in.}$ ), represents a volume increase of approximately $255 \mathrm{~m}^{3}\left(9,000 \mathrm{ft}^{3}\right)$ over the initial fill volume equivalent to a level of $983 \mathrm{~cm}$ ( $387 \mathrm{in.)}$. From this, the volume loss associated with water evaporation must be subtracted. The nominal estimate of water evaporation is $45 \mathrm{~kg} /$ day $\left(100 \mathrm{lb} /\right.$ day), which gives approximately $255 \mathrm{~m}^{3}$ $\left(9,000 \mathrm{ft}^{3}\right)$ evaporated in 15 years. However, the actual volume (and level) loss would be slightly less due to precipitation of dissolved solids. The actual volume (level) loss is estimated to be approximately $227 \mathrm{~m}^{3}\left(8,000 \mathrm{ft}^{3}\right)$ or $53 \mathrm{~cm}$ (2l in.). Approximately $7.6 \mathrm{~cm}$ ( 3 in.) of water was added to the tank during water lancing in the late 1980s (approximately $28 \mathrm{~m}^{3}\left[1,000 \mathrm{ft}^{3}\right]$ ). Therefore, the total void volume in the tank just prior to the October gas release event is estimated by this method at $453 \mathrm{~m}^{3}\left(16,000 \mathrm{ft}^{3}\right)$ or $109 \mathrm{~cm}$ (43 in.). Assuming that approximately $85 \mathrm{~m}^{3}\left(3,000 \mathrm{ft}^{3}\right)$ or $20 \mathrm{~cm}$ (8 in.) of this is in the crust and crnvective liquid layers, approximately $368 \mathrm{~m}^{3}$ $\left(13,000 \mathrm{ft}^{3}\right)$ or $89 \mathrm{~cm}(35 \mathrm{in.})$ are left in the non-convective liquid layer $793 \mathrm{~m}^{3}\left(28,000 \mathrm{ft}^{3}\right)$ when expanded to $\left.1 \mathrm{~atm}\right)$. This is close to the base case va'ue derived in Section 3.2.1, and is within the range of alternate cases considered. The gas volume calculated by this method is estimated to have an uncertainty of \pm 50 percent (primarily due to uncertainty in the quantity of water evaporated).

\subsection{GAS RELEASE}

The model of steady state gas release from the crust and convective liquid has been described previously. The model for rollover of the tank 
contents and release and/or retention of accumulated gas from the slurry is a complex one, requiring sophisticated multi-component, multi-phase, mult $i$ dimensional analysis. The characteristics of rollovers are conceived as being sensitive to material properties and initial gas distributions. The latter, in turn, may be dependent on prior gas release histories. Such analyses are beyond the scope of this assessment.

Just as a simple neutral buoyancy concept is used in this assessment to estimate the maximum potential gas accumulation, a similar concept is used to calculate the minimum quantity of gas which must be released. The model is as follows:

- All or part of the slurry rises under buoyant forces, just when it passes neutral buoyancy, to float on top of the convective liquid layer.

- The gas in this rising slurry expands due to the reduced hydrostatic head.

- At a minimum, the excess gas is released from the slurry, until the slurry at its new location returns to just below neutral buoyancy.

- At this point, the slurry can begin to sink; if cohesive or attractive forces are sufficient to entrain the remaining gas, it would be re-compressed and retained in the re-established slurry. An indication that such a phenomenon may be present has been noted.

NOTE: This is not a prediction of this behavior model, although it does appear that the gas release in GREs is much less than 100 percent efficient. This is simply a limiting-case model that is consistent with the observation that the slurry layer does re-establish itself after GREs. If it did not, the tank would have come to a condition with much or all of the solids in a solid/liquid/gaseous foam floating on the convective liquid.

NOTE: This analysis does not account for dissolved gases or water vapor. It has been estimated that the dissolved gases would account for no more than 2-3 percent of the total release, and water vapor would contribute less than 3 percent in situ and less than 5 percent in vented gas.

Consider a GRE involving 100 percent of the slurry, occurring at the time of maximum gas accumulation. Assuming no mixing with the convective liquid, the slurry layer would have a new pressure of 1.10 atm at the top, and $1.10+0.70=1.80$ at the bottom, for an average of $1.45 \mathrm{~atm}$. The original $388 \mathrm{~m}^{3}\left(13,700 \mathrm{ft}^{3}\right.$ ) (base case ) gas volume at 2.12 atm expands to $566 \mathrm{~m}^{3}$ $\left(20,000 \mathrm{ft}^{3}\right)$. However, $388 \mathrm{~m}^{3}\left(13,700 \mathrm{ft}^{3}\right)$ is all that is required for neutral buoyancy; the excess $178 \mathrm{~m}^{3}\left(6,300 \mathrm{ft}^{3}\right.$ ) (at $1.45 \mathrm{~atm}$ ) must be released for the slurry material to sink back to the bottom of the tank. The in-tank volumes of $178 \mathrm{~m}^{3}\left(6,300 \mathrm{ft}^{3}\right)$ released and $388 \mathrm{~m}^{3}\left(13,700 \mathrm{ft}^{3}\right)$ retained correspond to a minimum release of $258 \mathrm{~m}^{3}\left(9,100 \mathrm{ft}^{3}\right)(1 \mathrm{~atm})$ and a maximum retention of $564 \mathrm{~m}^{3}\left(19,900 \mathrm{ft}^{3}\right)$ (at $1 \mathrm{~atm}$ ). 
The results of this calculation for the three gas accumulation cases of Section 3.2.3 are given in Table 3-2 and 3-3. Similar calculations can be done for partial slurry rollover assumptions. The general conclusions are as follows:

- The minimum gas release (at $1 \mathrm{~atm}$ ) equals the accumulated gas in the involved slurry (at 1 atm) times

$$
\left[1-\frac{\rho \text { (floating) }}{\rho \text { (e bottom) }}\right]
$$

for the average slurry pressure in this tank, this multiplier is

$$
1-\frac{1.45}{2.12}=0.32
$$

- The maximum gas retention after a GRE equals the maximum potential accunnulation minus the actual GRE release.

A summary of the over-all assessment of potential gas inventories in tank 241-SY-101 is shown in Table 3-2. 
WHC-EP-0576

Table 3-2. Minimum Gas Release and Maximum Retention.

\begin{tabular}{|c|c|c|c|}
\hline Gas volume & $\begin{array}{l}\text { Basse casse } \\
\mathrm{m}^{3}\left(\mathrm{ft}^{3}\right)\end{array}$ & $\begin{array}{c}\text { A1ternate } \\
\text { çase } 1 \\
\mathrm{~m}^{3}\left(\mathrm{ft}^{3}\right)\end{array}$ & $\begin{array}{l}\text { Alternate } \\
\text { case } 2 \\
\mathrm{~m}^{3}\left(\mathrm{ft}^{3}\right)\end{array}$ \\
\hline $\begin{array}{l}\text { Slurry at bottom } \\
\text { in situ, } \mathrm{m}^{3}\left(\mathrm{ft}^{3}\right) \\
\text { c } 1 \mathrm{~atm} \mathrm{~m}^{3}\left(\mathrm{ft}^{3}\right)\end{array}$ & $\begin{array}{ll}388 & (13,700) \\
821 & (29,000)\end{array}$ & $\begin{array}{c}490(17,300) \\
1,039(36,700)\end{array}$ & $\begin{array}{ll}286 & (10,100) \\
606 & (21,400)\end{array}$ \\
\hline $\begin{array}{l}\text { Floating slurry: } \\
\text { original gas contents } \\
\text { in } \operatorname{tank} \mathrm{m}^{3}\left(\mathrm{ft}^{3}\right) \\
01 \mathrm{~atm}\end{array}$ & $\begin{array}{ll}566 & (20,000) \\
821 & (29,000)\end{array}$ & $\begin{array}{c}716(25,300) \\
1,039(36,700)\end{array}$ & $\begin{array}{l}419(14,800) \\
606(21,400)\end{array}$ \\
\hline $\begin{array}{l}\text { Floating slurry: } \\
\text { neutraliy buoyant } \\
\text { in tank, } \mathrm{m}^{3}\left(\mathrm{ft}^{3}\right) \\
0_{1 \mathrm{~atm}}\end{array}$ & $\begin{array}{l}388(13,700) \\
564(19,900)\end{array}$ & $\begin{array}{l}490(17,300) \\
711(25,100)\end{array}$ & $\begin{array}{l}286(10,100) \\
413(14,600)\end{array}$ \\
\hline $\begin{array}{l}\text { Minimum release } \\
\text { o original pressure } \\
\text { e floating pressure } \\
\text { 0 1 atm }\end{array}$ & $\begin{array}{l}122(4,300) \\
178(6,300) \\
258(9,100)\end{array}$ & $\begin{array}{ll}156 & (5,500) \\
227 & (8,000) \\
329 & (1,600)\end{array}$ & $\begin{aligned} 91 & (3,200) \\
133 & (4,700) \\
193 & (6,800)\end{aligned}$ \\
\hline $\begin{array}{l}\text { Maximum retention: } \\
\text { o original pressure } \\
\text { e floating pressure } \\
\text { e } 1 \mathrm{~atm}\end{array}$ & $\begin{array}{l}266(9,400) \\
388(13,700) \\
564(19,900)\end{array}$ & $\begin{array}{l}334(11,800) \\
490(17,300) \\
711(25,100)\end{array}$ & $\begin{array}{ll}195 & (6,900) \\
286 & (10,100) \\
413 & (14,600)\end{array}$ \\
\hline
\end{tabular}

NOTE: These values do not include any estimate or allowance for net positive buoyancy to overcome slurry cohesive shear strength. 
Table 3-3. Gas Inventory Summary.

\begin{tabular}{|l|c|c|c|}
\hline \multicolumn{1}{|c|}{ Layer } & $\begin{array}{c}m^{3}\left(\mathrm{ft}^{3}\right) \text { In place } \\
\text { pre-GRE post-GRE }\end{array}$ & $\begin{array}{c}m^{3}\left(\mathrm{ft}^{3}\right) \text { a } 1 \text { Atm } \\
\text { pre-GRE post-GRE }\end{array}$ & $\begin{array}{c}\text { S Surface cm (in.) } \\
\text { pre-GRE post-GRE }\end{array}$ \\
\hline "Crust" & $57(2,000)$ & $57(2,000)$ & $13(5)$ \\
\hline Convective liquid & $28(1,000)$ & $<57(<2,000)$ & $8(3)$ \\
\hline \multirow{3}{*}{ slurry } & $286-195(10,100-6,900)$ & $606-413(21,400-14,600)$ & $69-48(27-19)$ \\
& $388-266(13,700-9,400)$ & $821-564(29,000-19,000)$ & $94-66(37-26)$ \\
& $490-334(17,300-11,800)$ & $1,039-711(36,700-25,100)$ & $119-81(47-32)$ \\
\hline \multirow{3}{*}{ Total } & & & $89-69(35-27)$ \\
& & & $114-86(45-34)$ \\
& & & $140-102(55-40)$ \\
\hline
\end{tabular}

GRE = Gas release events

\subsection{UNCERTAINTY ASSESSMENT}

The range of uncertainty for this assessment is estimated as follows.

a. Gas Generation Rate-- The absolute uncertainty is large ( \pm 25 percent). The impact on the maximum gas accumulation estimate is small. The uncertainty is an important consideration relative to predicting the effects of mitigation concepts which involve significant changes in temperature, radiation levels, or chemical or physical characteristics of the waste.

b. Gas Release--This assessment estimates only a minimum gas release, and a corresponding maximum gas retention, for GREs. The uncertainty in the maximum gas release fraction is not bounded or assessed in this study. Detailed modeling and numerical analysis is required to predict gas release dynamics and to perform a systematic sensitivity study.

c. Gas Accumulation--Significant uncertainty in gas accumulation is associated with the density and packing fraction of the solid slurry components ( \pm 25 percent). An uncertainty is associated with yield properties of the material and the corresponding potential for sustaining positive buoyancy forces (estimated as an uncertainty of about +10 percent, -0 ). Overal1 uncertainty in maximum gas accumulation ( \pm 30 percent). 


\subsection{REFERENCES}

Allemann, R. T., A. I. Antoniak, L. L. Eylers, L. M. Liljegren, and J. S. Roberts, 1992, Conceptual Models for Waste Tank Mechanistic Analysis - Status Report - January 1991, PNL-8011, Pacific Northwest Laboratory, Richland, Washington.

Allemann, R. T., 1992, Physical Mechanisms Contributing to the Episodic Gas Release From Hanford Tank 241-SY-101, PNL-SA-20353, Pacific Northwest Laboratory, Richland, Washington.

Babad, H., G. D. Johnson, D. A. Reynolds, and D. M. Strachan, 1992 , Understanding Cyclic Venting Phenomena in Hanford Site High Level Waste Tank: The Evaluation of Tank 241-SY-101, WHC-SA-1364-FP, Westinghouse Hanford Coinpany, Richland, Washington.

Barker, J. J., T. M. Burke, K. G. Carothers, and D. A. Reynolds, 1991, WHC-SD-WM-PE-041, Rev. 0, Evaluation of October 24, 1990 Tank 241-SY-101 Gas Release Event, Westinghouse Hanford Company, Richland, Washington.

Burke, T. M., K. G. Carothers, S. M. Joyce, and A. L. Pajunen, 1991, Evaluation of April 19, 1990, Tank 241-SY-101 Gas Release Event, WHC-SD-WM-PE-039, Westinghouse Hanford Company, Richland, Washington.

Erhart, M. F., 1992, Evaluation of December 1991 Tank 241-SY-101 Gas Release Event, WHC-SD-WM-PE-046, Rev. 0, Westinghouse Hanford Company, Richland, Washington.

Herting, D. L., D. B. Bechtold, B. A. Crawford, T. L. Welsh, and L. Jensen, 1992, Laboratory Characterization of Samples Taken in May 1991 From Hanford Waste Tank 241-SY-101, WHC-SD-WM-DTR-024, Rev. 0, Westinghouse Hanford Company, Richland, Washington.

Honeyman, J. 0., and M. Solbakken, 1978, Double Shell Slurry Process Test Evaluation, RHO-CD-394, Rockwell Hanford Operations, Richland, Washington.

Koontz, R. L., 1986, Double-Shell Tank Farm Facility Safety Analysis Report, WHC-SD-WM-SAR-016, Rev. 1, Westinghouse Hanford Company, Richland, Washington.

Meise1, D., M. C. Sauer, Jr., C. D. Jonah, H. Diamond, M. S. Matheson, F. Barnabas, E. Cerny, and Y. Cheng, 1992, Radiolytic and Radiolytic-Induced Gases in Simulated Waste Solutions, Waste Management Conference, Tucson, Arizona.

Reynolds, D. A., 1992, Tank 101-SY Window C Core Sample Results and Interpretation, WHC-EP-0589, Rev. O, Westinghouse Hanford Company, Richland, Washington.

Wallace, G. B., 1969, One Dimensional, Two-Phase Flow, McGraw-Hill, New York, New York. 
WHC-EP-0576

This page intentionally left blank. 
WHC-EP-0576

APPENDIX A

GAS RELEASE EVENT VERTICAL TEMPERATURE PROFILES:

OCTOBER 1990 AND DECEMBER 1991 
WHC-EP-0576

This page intentionally left blank. 
Figure A-1. Temperature Profiles Associated with the October 24, 1990 Vent Cycle.

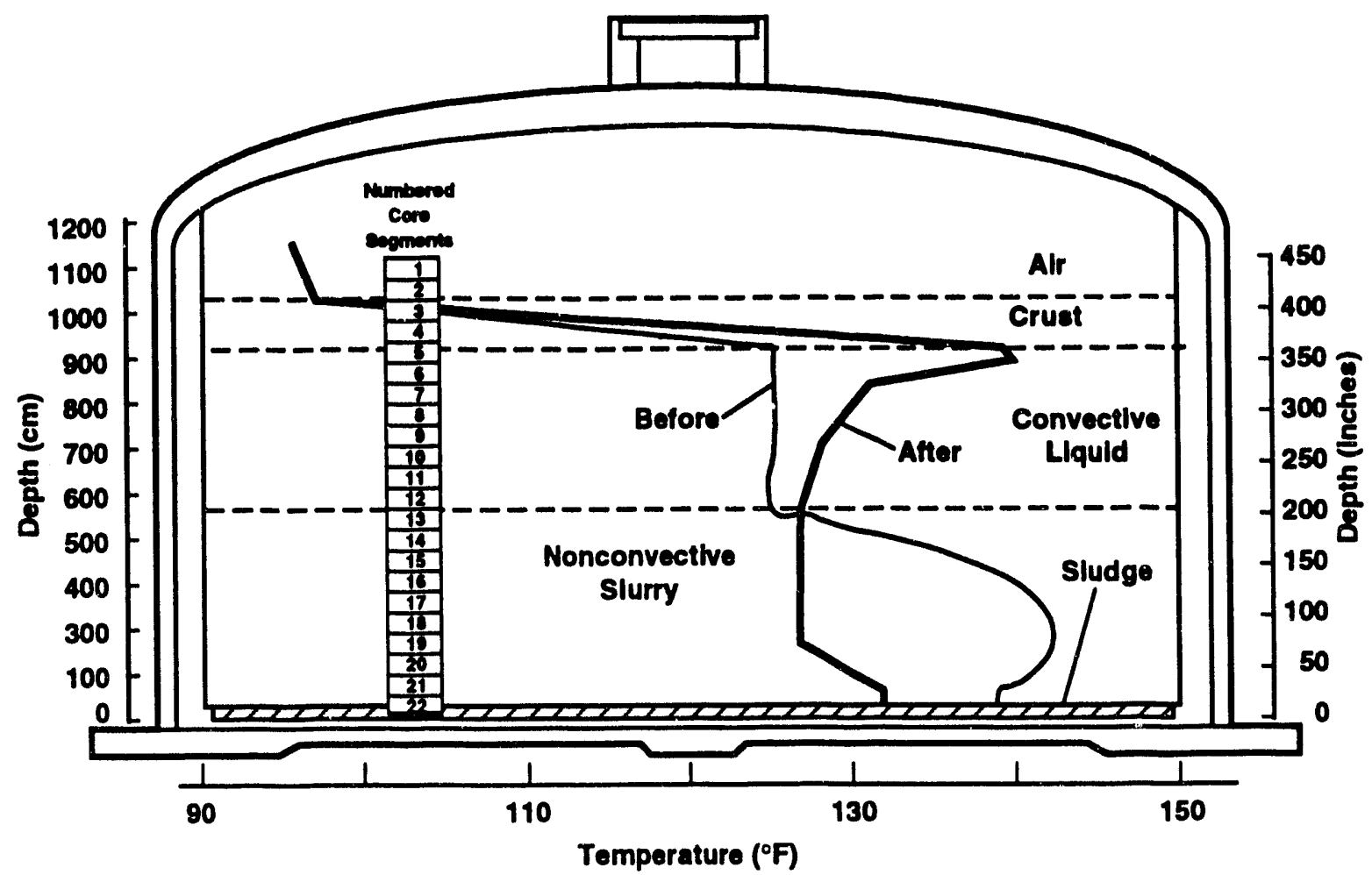

29208019.7 
Figure A-2. Thermocouple Temperature Profile Three-Dimensional Plot Looking Forward in Time and Down in Depth; October 1990 Gas Release Event

Tank 101-SY October 24, 1990

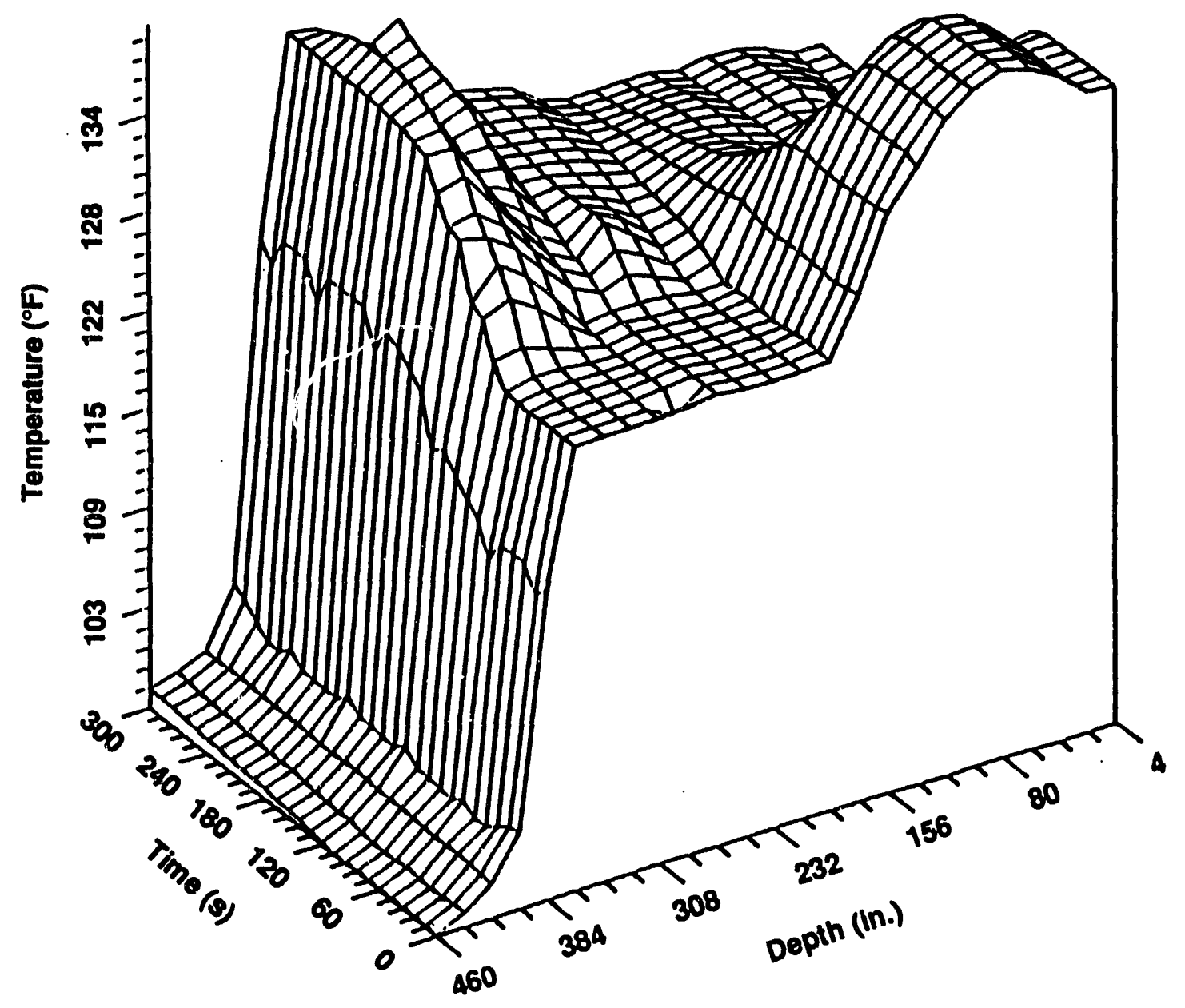




\section{WHC-EP-0576}

Figure A-3. Thermocouple Temperature Comparison Before, During and After Gas Release Event - December 1991.

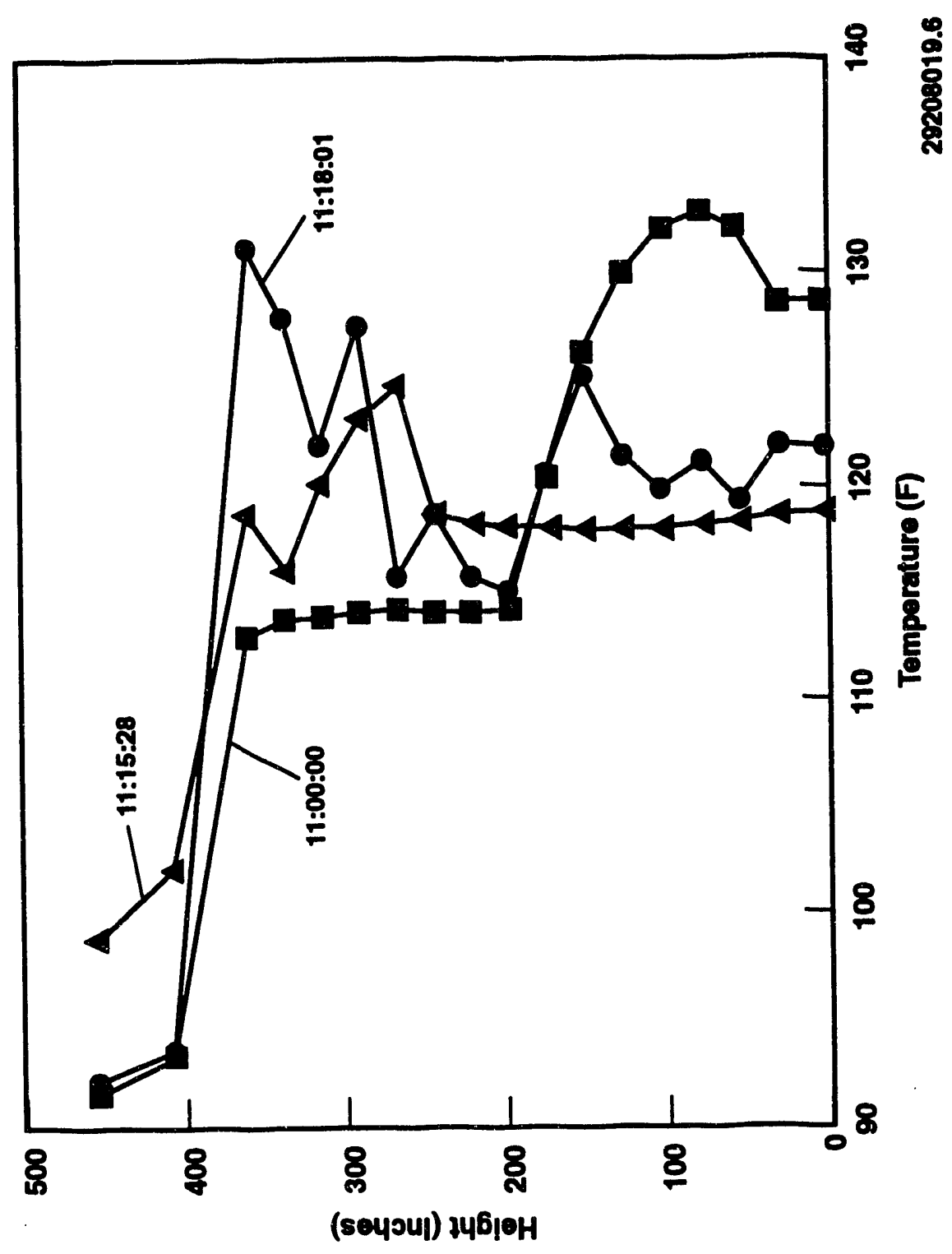


WHC-EP-0576

This page intentionally left blank. 
WHC-EP-0576

APPENDIX B

PHYSICAL PROPERTIES OF "WINDOW C" CORE SAMPLES 
WHC-EP-0576

This page intentionally left blank. 
Table B-1.* Physical Properties of Samples from Tank 241-SY-101.

\begin{tabular}{|c|c|c|c|c|}
\hline Property & $32{ }^{\circ} \mathrm{C}$ & $50^{\circ} \mathrm{C}$ & $65^{\circ} \mathrm{C}$ & $80^{\circ} \mathrm{C}$ \\
\hline \multicolumn{5}{|c|}{ Segment 19 nonconvective slurry } \\
\hline Density $(\mathrm{g} / \mathrm{mL})--$ bulk & 1.68 & 1.66 & 1.66 & 1.74 \\
\hline Density--centrifuged supernate & 1.50 & 1.46 & 1.44 & 1.44 \\
\hline Density-centrifuged solids & 1.75 & 1.75 & 1.73 & 2.03 \\
\hline Volume \% settled solids & $100 \%$ & $100 \%$ & $100 \%$ & $100 \%$ \\
\hline Volume \% centrifuged solids & $78 \%$ & $72 \%$ & $65 \%$ & $62 \%$ \\
\hline Wt \% centrifuged solids & $79 \%$ & $76 \%$ & $67 \%$ & $72 \%$ \\
\hline Shear strength (dynes $/ \mathrm{cm}^{2}$ ) & 15,000 & 6,400 & 3,000 & 5,100 \\
\hline Wt $\%$ water, gravimetric & \multicolumn{4}{|c|}{$31.4 \%$} \\
\hline \multicolumn{5}{|c|}{ Segment 8 convective 1 iquid } \\
\hline Density $(\mathrm{g} / \mathrm{mL})--$ bulk & 1.53 & 1.54 & 1.54 & 1.48 \\
\hline Density--centrifuged supernate & 1.46 & 1.45 & 1.47 & 1.43 \\
\hline Density--centrifuged solids & 1.93 & 1.85 & 1.82 & 2.16 \\
\hline Volume $\%$ settled solids & $44 \%$ & $48 \%$ & $54 \%$ & $56 \%$ \\
\hline Volume $\%$ centrifuged solids & $22 \%$ & $23 \%$ & $20 \%$ & $8 \%$ \\
\hline Wt \% centrifuged solids & $28 \%$ & $27 \%$ & $24 \%$ & $10 \%$ \\
\hline Shear strength (dynes $/ \mathrm{cm}^{2}$ ) & $<530$ & & & \\
\hline Wt $\%$ water, gravimetric & \multicolumn{4}{|c|}{$38.9 \%$} \\
\hline \multicolumn{5}{|c|}{ Segment 22 sludge } \\
\hline Density $(\mathrm{g} / \mathrm{mL})$--bulk & 1.71 & 1.71 & 1.71 & 1.70 \\
\hline Density--centrifuged supernate & 1.46 & 1.51 & 1.52 & 1.53 \\
\hline Density--centrifuged solids & 1.78 & 1.82 & 1.79 & 1.79 \\
\hline Volume $\%$ settled solids & $100 \%$ & $100 \%$ & $100 \%$ & $99 \%$ \\
\hline Volume $\%$ centrifuged solids & $79 \%$ & $73 \%$ & $68 \%$ & $64 \%$ \\
\hline Wt. $\%$ centrifuged solids & $83 \%$ & $78 \%$ & $72 \%$ & $68 \%$ \\
\hline Shear strength (dynes $/ \mathrm{cm}^{2}$ ) & 116,000 & 26,400 & 4,000 & 14,000 \\
\hline Wt. \% water, gravimetric & \multicolumn{4}{|c|}{$28.5 \%$} \\
\hline
\end{tabular}

*Herting, D. L., D. B. Bechtold, B. A. Crawford, T. L. Welsh, and L. Jensen, 1992, Laboratory Characterization of Samples Taken in May 1991 From Hanford Waste Tank 241-SY-101, WHC-SD-WM-DTR-024, Rev. 0, Westinghouse Hanford Company, Richland, Washington. 
Table B-2. Comparison of Pacific Northwest laboratory Physical Results with Process Control Laboratories Processing Data.

\begin{tabular}{|c|c|c|c|c|}
\hline Property & $\begin{array}{l}\text { Room temp. } \\
\text { (PNL) }\end{array}$ & $\begin{array}{l}\text { Room temp. } \\
\text { (West inghouse } \\
\text { Hanford) }\end{array}$ & $\begin{array}{c}65^{\circ} \mathrm{C} \\
(\mathrm{PNL})\end{array}$ & $\begin{array}{c}60{ }^{\circ} \mathrm{C} \\
\text { (West inghouse } \\
\text { Hanford) }\end{array}$ \\
\hline \multicolumn{5}{|c|}{ Segment $19 *$ and 22* (nonconvective layer) } \\
\hline Density $(\mathrm{g} / \mathrm{mL})$--bulk & 1.70 & 1.64 & 1.68 & \\
\hline $\begin{array}{l}\text { Density--centrifuged } \\
\text { supernate }\end{array}$ & 1.48 & & 1.48 & 1.48 \\
\hline Density--centrifuged solids & 1.76 & & 1.76 & 1.70 \\
\hline Volume $\%$ centrifuged solids & $78 \%$ & & $68 \%$ & $76 \%$ \\
\hline Wt $\%$ centrifuged solids & $81 \%$ & & $70 \%$ & $79 \%$ \\
\hline Wt $\%$ water** & $30.0 \%$ & $\begin{array}{l}32.5 \% \\
(33.3)\end{array}$ & & \\
\hline \multicolumn{5}{|c|}{ Segment 8 (convective layer) } \\
\hline Density--bulk & 1.53 & 1.55 & 1.54 & \\
\hline $\begin{array}{l}\text { Density--centrifuged } \\
\text { supernate }\end{array}$ & 1.46 & & 1.47 & 1.51 \\
\hline Density--centrifuged solids & 1.93 & & 1.83 & 1.68 \\
\hline Volume \% centrifuged solids & $22 \%$ & & $20 \%$ & $18 \%$ \\
\hline Wt $\%$ centrifuged solids & $28 \%$ & & $24 \%$ & $25 \%$ \\
\hline Wt \% water & 38.9 & 36.3 & & \\
\hline
\end{tabular}

*Average of values obtained from composites 3, and 4, processed at Westinghouse Hanford and Segments 19 and 22 analyzed at PNL.

**Value for wt $\%$ water determined by Westinghouse Hanford Company was obtained from Segment 19 TGA and Segment 22 TGA determinations. The value shown in parentheses is the average result of two determinations made by Karl Fischer titration.

There is good agreement between the two measurements for most of the values shown. Densities reported for the centrifuged solids, centrifuged liquids and bulk samples are all within $5 \%$ for the average results obtained from Segment 19 and 22 and those of the processed composite samples. All density and weight percent water determinations differ by no more than $10 \%$. The volume and weight percent centrifuged solids for Segment 19 and those obtained from composite 3 and 4 averages exhibit larger discrepancies. Generally, the volume and weight percent results are larger for centrifuged solids processed by Westinghouse Hanford. This discrepancy may be due to the temperature difference between methods used or from incomplete separation of liquids from solids in the processed composites. 
Table B-3. Physical Properties of Convective Liquid Samples from Tank 241-SY-101.

\begin{tabular}{|c|c|c|c|c|}
\hline \multicolumn{5}{|c|}{ Segment 4} \\
\hline Property & $32{ }^{\circ} \mathrm{C}$ & $50^{\circ} \mathrm{C}$ & $65^{\circ} \mathrm{C}$ & $80^{\circ} \mathrm{C}$ \\
\hline Density $(\mathrm{g} / \mathrm{mL})$--bulk & 1.50 & 1.51 & 1.50 & 1.50 \\
\hline --centrifuged supernate & 1.43 & 1.43 & 1.41 & 1.43 \\
\hline --centrifuged solids & 2.1 & 1.9 & 1.9 & 1.9 \\
\hline Volume $\%$ settled solids & $60 \%$ & $60 \%$ & $58 \%$ & $51 \%$ \\
\hline Volume $\%$ centrifuged solids & $5 \%$ & $7 \%$ & $7 \%$ & $7 \%$ \\
\hline wt $\%$ centrifuged solids & $10 \%$ & $9 \%$ & $9 \%$ & $9 \%$ \\
\hline Wt \% water (gravimetric) & \multicolumn{4}{|c|}{$39.4 \%$} \\
\hline \multicolumn{5}{|c|}{ Segment 8} \\
\hline Density $(\mathrm{g} / \mathrm{mL})--$ bulk & 1.53 & 1.54 & 1.54 & 1.48 \\
\hline --centrifuged supernate & 1.46 & 1.45 & 1.47 & 1.43 \\
\hline --centrifuged solids & 1.93 & 1.85 & 1.82 & 2.16 \\
\hline Volume $\%$ settled solids & $44 \%$ & $48 \%$ & $54 \%$ & $56 \%$ \\
\hline Volume $\%$ centrifuged solids & $22 \%$ & $23 \%$ & $20 \%$ & $8 \%$ \\
\hline wt $\%$ centrifuged solids & $28 \%$ & $27 \%$ & $24 \%$ & $10 \%$ \\
\hline Wt $\%$ water (gravimetric) & \multicolumn{4}{|c|}{$38.9 \%$} \\
\hline \multicolumn{5}{|c|}{ Segment 13} \\
\hline Density $(\mathrm{g} / \mathrm{mL})--$ bulk & 1.44 & 1.45 & 1.45 & 1.44 \\
\hline --centrifuged supernate & 1.43 & 1.42 & 1.41 & 1.38 \\
\hline --centrifuged solids & 2.1 & 2.1 & 2.0 & 2.2 \\
\hline Volume \% settled solids & $39 \%$ & $37 \%$ & $39 \%$ & $40 \%$ \\
\hline Volume \% centrifuged solids & $7 \%$ & $7 \%$ & $7 \%$ & $6 \%$ \\
\hline wt $\%$ centrifuged solids & $11 \%$ & $10 \%$ & $9 \%$ & $8 \%$ \\
\hline Wt $\%$ water (gravimetric) & \multicolumn{4}{|c|}{$35.0 \%$} \\
\hline
\end{tabular}


Table B-4. Physical Properties of Non-Convective Samples from Tank 241-SY-101.

\begin{tabular}{|c|c|c|c|c|}
\hline \multicolumn{5}{|c|}{ Segment 15} \\
\hline Property & $32^{\circ} \mathrm{C}$ & $500^{\circ} \mathrm{C}$ & $65^{\circ} \mathrm{C}$ & $80^{\circ} \mathrm{C}$ \\
\hline Density $(\mathrm{g} / \mathrm{mL})$--bulk & 1.67 & 1.70 & 1.70 & 1.66 \\
\hline --centrifuged supernate & 1.48 & 1.58 & 1.50 & 1.55 \\
\hline --centrifuged solids & 1.74 & 1.75 & 1.76 & 1.79 \\
\hline Volume $\%$ settled solids & $100 \%$ & $100 \%$ & $100 \%$ & $98 \%$ \\
\hline Volume $\%$ centrifuged solids & $88 \%$ & $80 \%$ & $75 \%$ & $69 \%$ \\
\hline wt $\%$ centrifuged solids & $88 \%$ & $83 \%$ & $78 \%$ & $74 \%$ \\
\hline Shear strength (dynes $/ \mathrm{cm}^{2}$ ) & 47,500 & 7,300 & 21,000 & 5,300 \\
\hline Wt $\%$ water (gravimetric) & \multicolumn{4}{|c|}{$28.4 \%$} \\
\hline \multicolumn{5}{|c|}{ Segment 19} \\
\hline Density $(\mathrm{g} / \mathrm{mL})$--bulk & 1.68 & 1.66 & 1.66 & 1.74 \\
\hline --centrifuged supernate & 1.50 & 1.46 & 1.44 & 1.44 \\
\hline --centrifuged solids & 1.75 & 1.75 & 1.73 & 1.90 \\
\hline Volume $\%$ settled solids & $100 \%$ & $100 \%$ & $100 \%$ & $100 \%$ \\
\hline Volume $\%$ centrifuged solids & $78 \%$ & $72 \%$ & $65 \%$ & $62 \%$ \\
\hline wt $\%$ centrifuged solids & $79 \%$ & $76 \%$ & $67 \%$ & $68 \%$ \\
\hline Shear strength (dynes $/ \mathrm{cm}^{2}$ ) & 15,000 & 6,400 & 3,000 & 5,100 \\
\hline Wt $\%$ water (gravimetric) & \multicolumn{4}{|c|}{$31.4 \%$} \\
\hline
\end{tabular}


Table B-5. Physical Properties of Sludge Samples from Tank 241-SY-101.

\begin{tabular}{|l|c|c|c|c|}
\hline \multicolumn{5}{|c|}{ Segment 22} \\
\hline Property & $32^{\circ} \mathrm{C}$ & $50^{\circ} \mathrm{C}$ & $65^{\circ} \mathrm{C}$ & $80^{\circ} \mathrm{C}$ \\
\hline Density (g/mL)--bulk & 1.71 & 1.71 & 1.71 & 1.70 \\
\hline --centrifuged supernate & 1.46 & 1.51 & 1.52 & 1.53 \\
\hline --centrifuged solids & 1.78 & 1.82 & 1.79 & 1.79 \\
\hline Volume \% settled solids & $100 \%$ & $100 \%$ & $100 \%$ & $99 \%$ \\
\hline Volume \% centrifuged solids & $79 \%$ & $73 \%$ & $68 \%$ & $64 \%$ \\
\hline wt \% centrifuged solids & $83 \%$ & $78 \%$ & $72 \%$ & $68 \%$ \\
\hline Shear strength (dynes $/ \mathrm{cm}^{2}$ ) & 116,000 & 26,400 & 4,000 & 14,000 \\
\hline Wt \% water (gravimetric) & \multicolumn{5}{|c|}{$28.5 \%$} \\
\hline
\end{tabular}


WHC-EP-0576

This page intentionally left blank. 
WHC-EP-0576

APPENDIX C

GAS RELEASE PHENOMENON: TANK 241-SY-101

C-1 
WHC-EP-0576

This page intentionally left blank. 
From: Environment, Safety, Health, and Quality Assurance

Phone: 6-0644 B3-55

Date: December 31, 1991

Subject: 101-SY GAS RELEASE PHENOMENON

To:
Rudy Allemann
K7-15
cc:
G. M. Christensen
W. L. Knecht HO-34
H4-23
D. D. Stepnewski H5-32
DES-File/LB

Thanks for sending me the reports of your modelling analysis on the subject. As we discussed a couple of weeks ago, I have looked briefly into a onedimensional model which assumes that gas is generated at a uniform rate in the liquid phase of the slurry, and is released whenever the slurry achieves a net positive buoyancy for the entire slurry layer above some level.

The model assumes the slurry bed has sufficient mechanical strength to act as a barrier, preventing the rise of lower level buoyant slurry through heavier over-lying layers. The slurry then behaves as follows:

1. Starting with a uniform gas content, the slurry grows lighter, by expulsion of liquid from the settled bed, and first becomes buoyant at the top surface of the slurry.

2. Release of gas from the top layer(s) permits the slurry bed to resettle on top, and a period of time elapses until gas bulldup lower in the bed produces enough buoyancy to balance the heavier slurry above.

3. The slurry layer above the neutral buoyancy point in the bed rises, releasing gas from all layers above the neutral buoyancy level.

4. The layers below the neutral buoyancy point are assumed to be unaffected by the gas release above, except that the releases are followed by resettling of the above solids, increasing the weight of solids which must be overcome by buoyant forces.

5. Eventually, the neutral buoyancy point works its way to the bottom; if the gas release at each slurry ifft was assumed to be 100 percent, the process would simply repeat - but if the release is less than 100 percent, the system cont inues to remember its history, and subsequent releases are affected by the gas which remains in the slurry. 
Rudy Allemann

Page 2

December 31,1991

I performed a scoping calculation using the following parameters:

- slurry constituents:

- 50\% volume solids $120 \mathrm{lb} / \mathrm{ft}^{3}$ at top of slurry, increasing to $60 \%$ at bottom

- liquid $90 \mathrm{lb} / \mathrm{ft}^{3}$

- gas $1 \mathrm{lb} / \mathrm{ft}^{3}$ e 1 atmosphere

(gas accumulation displaces liquid, at no change in slurry volume).

- gas generation rate:

$-0.002 \frac{\mathrm{ft}^{3}}{\mathrm{ft}^{3}}$ (gas) (1iquid) 1 atm pressure

- gas release on slurry rise event:

- 50\% of gas at all levels above neutral buoyancy

- zero at lower levels

- model geometry

- $10 \mathrm{ft}$. overlying liquid

- $18 \mathrm{ft}$. Of slurry ( $9-2 \mathrm{ft}$. layers modelled)

With these parameters, and starting with a uniform gas volume of $7.5 \%$ in the slurry, slurry rise events (burps) were calculated to occur at times of:

Time Time Interval

$\begin{array}{rr}135 \text { days } & \text { N/A } \\ 197 & 62 \\ 304 & 107 \\ 472 & 168 \\ 533 & 61 \\ 657 & 124 \\ 788 & 131 \\ 866 & 78 \\ 999 & 133 \\ 1081 & 82\end{array}$

The gas distribution in the slurry and the gas release per event vary widely. Figure 1 shows the calculated gas volume release (1 atm pressure) for the burp events plotted in sequence (not scaled to time). 
Rudy Allemann

Page 3

December 31, 1991

Figure 2 shows the average slurry density at and above the plotted layers at the time of each event. The gas release occurs when the equivalent density at any layer goes below $90\left(1 \mathrm{~b} / \mathrm{ft}^{3}\right)$, and $50 \%$ of the gas at and above that layer is released at that time. The bed then resettles and awaits enough gas buildup to trigger the next event. (I left the $50 \%$ gas at its original layers, rather than mix them up.)

Figure 3 shows the local slurry densities at the onset of each event.

The significant aspects of this model are:

- $\quad$ some mechanical strength of the settled bid is assumed

- viscosity of the fluid is neglected

Since the calculated behavior seems qualitatively consistent with observations, these may be reasonable. If so, there is a simple implication for remediation: fluidizing the slurry bed will eliminate the episodic gas releases. This is consistent with remediation concepts aimed at "mobilizing" the slurry, i.e., keeping the solid particles in suspension by some means of stirring the tank contents.

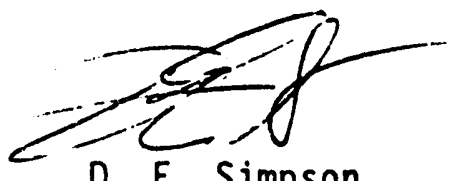

Consultant

$k b$

Attachments 3 
WHC-EP-0576

Figure C-1.

\section{Gas Release Per Event}

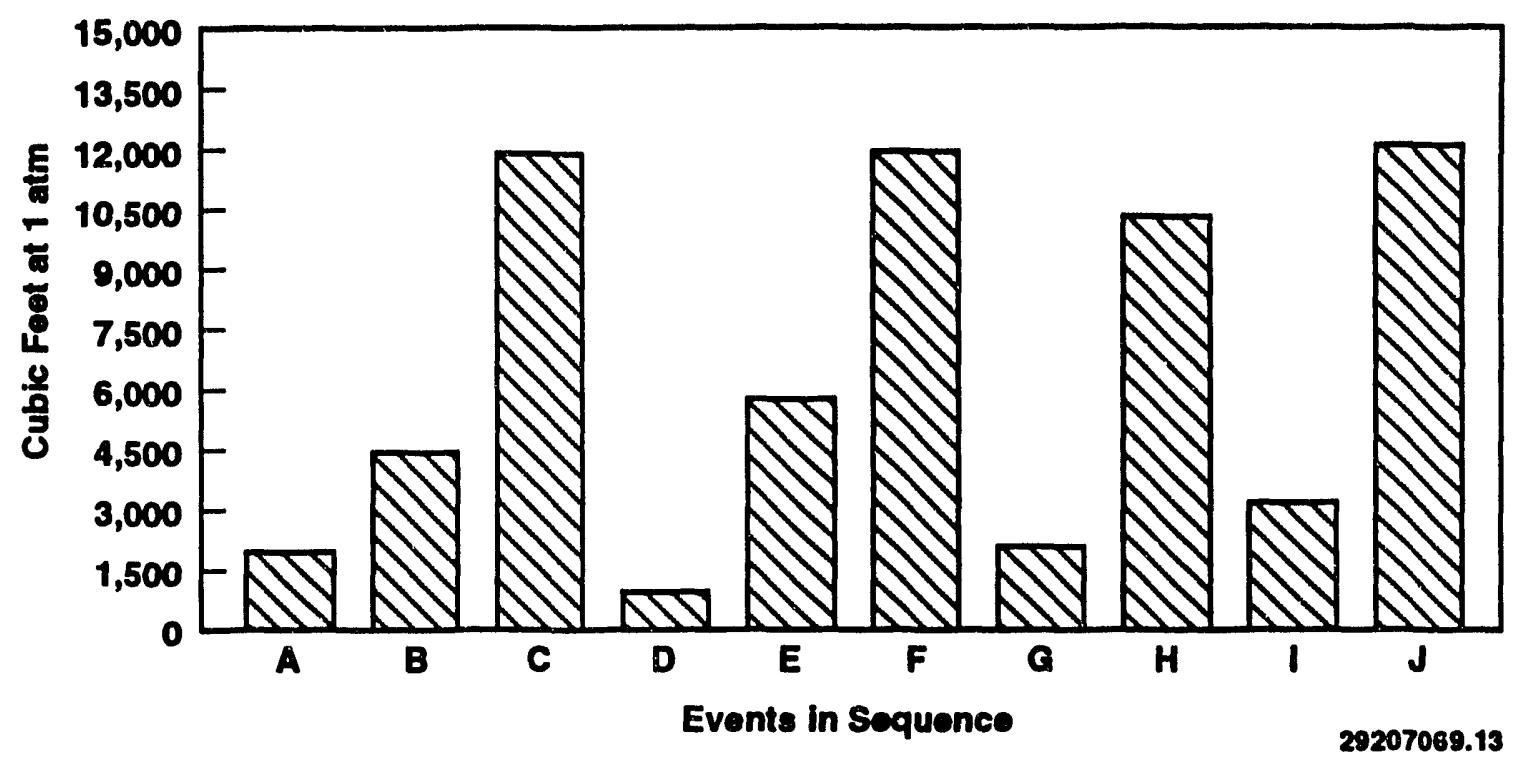


WHC-EP-0576

Figure C-2.

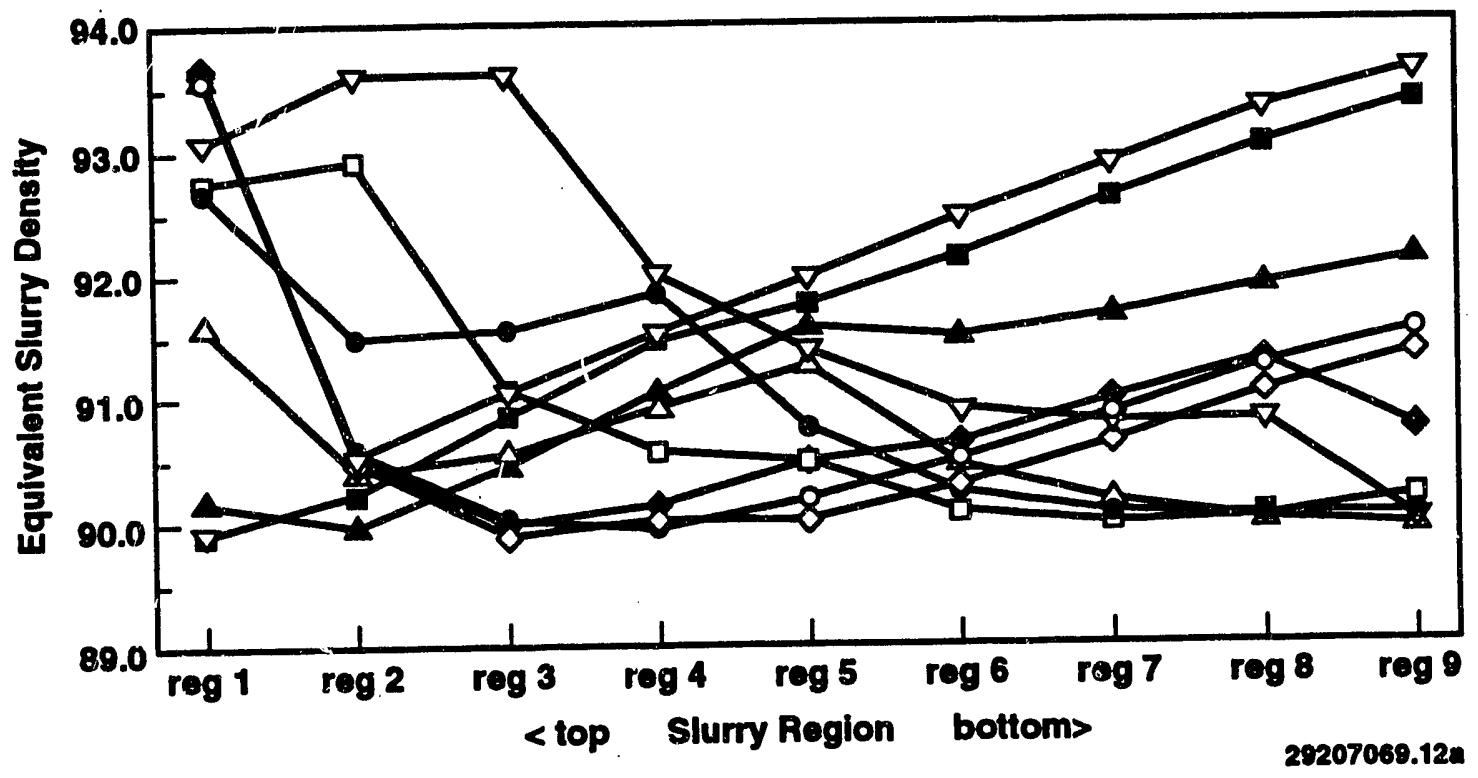


WHC-EP-0576

Figure $\mathrm{C}-3$

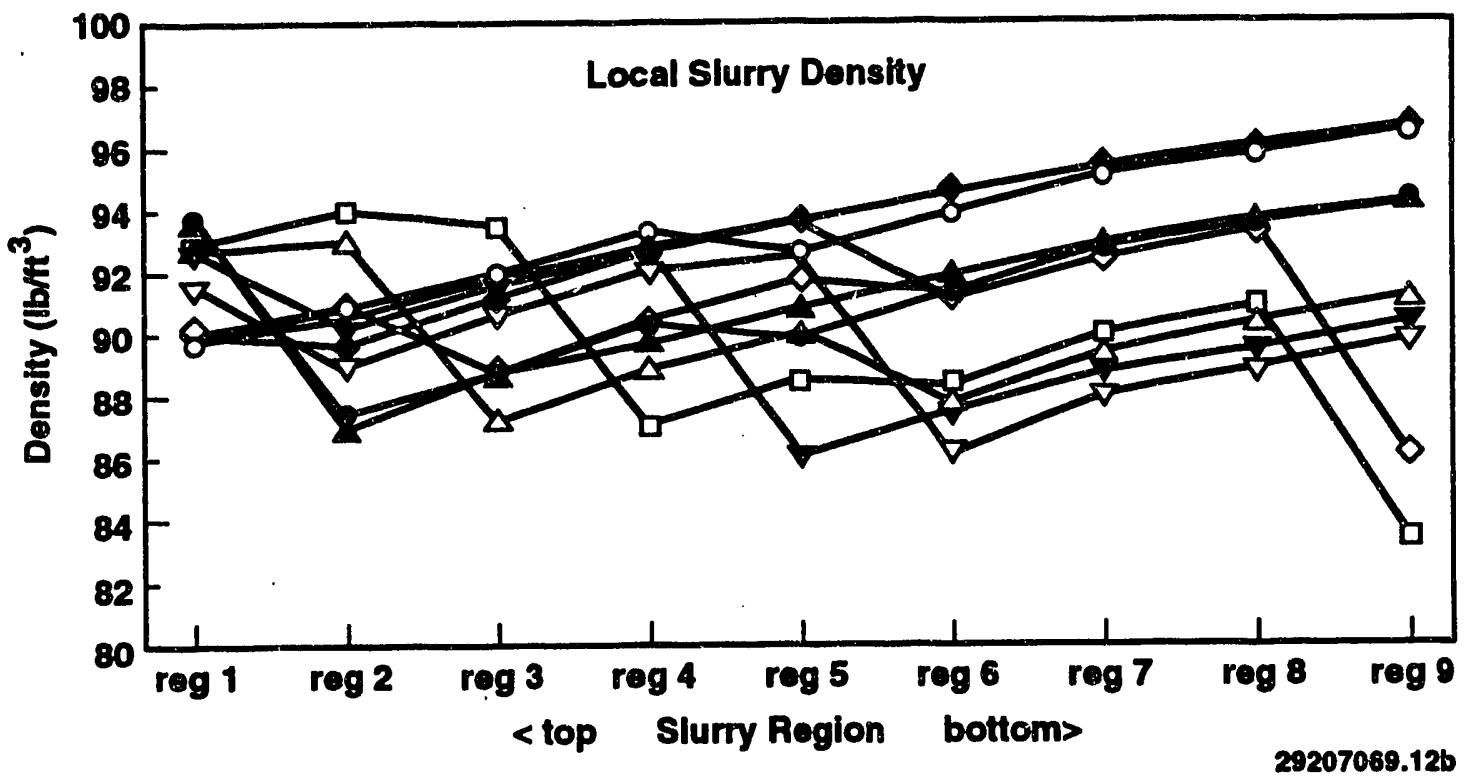


WHC-EP-0576

APPENDIX D

PHYSICAL MECHANISIS CONTRIBUTING TO THE EPISODIC GAS RELEASE FRON HANFORD TANK 241-SY-101 
WHC-EP-0576

This page intentionally left blank.

D-2 
Rudolph T. Allemanan, Staft Scleatist Paclinc Northmest Laboratory Aaslytle Sciences Department PO Box 998

Richland, Washiaglon 99352 (509) 375-2151

\section{ABSTKACT}

Volume growith of contents in a waste storage tank at JJanford is accompanied by episodle releases of gas and a rise in the level of tank coateats. A theory is presented to describe how the gas is retained in the waste and how It is relensed. The theory postulates that somewhat coliesive gobs of siudge rise from the lower reglons of the tank us buogancy overcomes the coheslve strength of the slurrys this quanalitalively explains several of the measured phenoniena and qualliatively exploins other observalions.

\section{INTRODUCTION}

Tunk 241-5Y-101 b a $3.8 \times 10^{6}$ lliter (1 million gallon), double wall, weste storage tank (see Figure 1) that hus been used to store enncentrated rodlooctlve delense wasle since 1977.

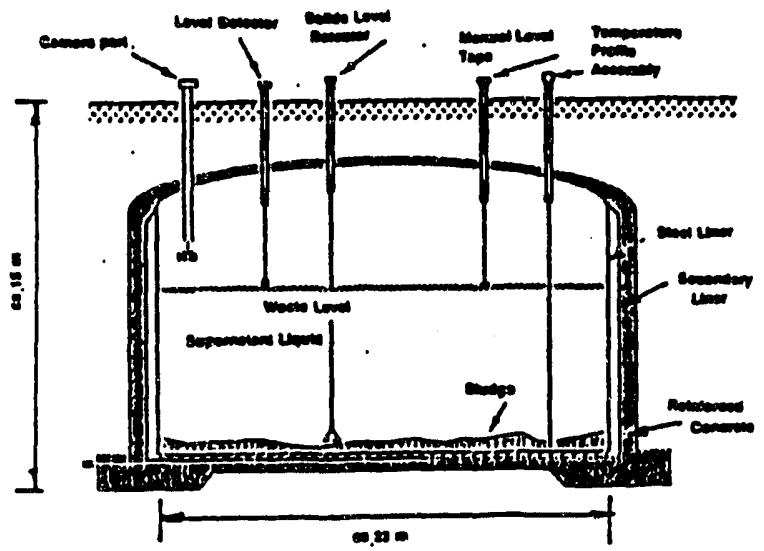

Figure 1. Configuration of llaaford Double Shell Waste Tank, 241.SY-101

Several different baiches of waste were added to the tunk from 1977 until 1980. Moniloring of the tunk Iliquid level showed that the level of Auid was sisiag in the tanks this phenomenon was lermed "level growih".
The general rise in level was intermpled partodically by level drops, which were quile rapld, oceurring in less than $I$ day. The level drope were aceosapanted by the sadden relense of gas into the tonk head spage and through the Altered vent system. These relenses, termed burps", were fowad to contain mon-radionetive gases, but hydrogen and altrous oxide were present la polentlully nammable ratios and conceatrations in some large releases. This frect colezortzed the tuak as a sufety coscern. Resenreh lavestigatias the cawses of ges geacration and the larye periodic releases was Ialliated to Mad ways to alligate the probleme

This sufety problem would be ellininated if the gas production were stopped or if the gas was released in smalker baiches, or stendlly, ratber than in lorge "burps". The purpose of this researeh was to explore physted mechanisms involved in the "borp" phenomenon in provide lasights into what physical anlligation techniques might be feasible, partleuterty if other schemes that stop the generation of nammable gases were not feasible. This paper discusses some analyses performed, that wers fuadamentally based os dals obtained by Westinghouse Ilaxford Company, operators of the lank farm. The analyses supgest a mechanism by which the gases are retained and periodically released in large amounts. The surorested meehanism also agrees with olher data obtained from analyses of tank 241-5Y-101.

\section{TANK 241.SY-101 DATA}

\section{A. Level}

Figure 2 shows an example of the long-term history of the waste level in the tank. The sudden large drops in level are accompanied by a release of cunsiderable volumes of gus. The level drops have oceurred in a range of sizes and a size spectrum shows that small drops are statistically more frequent than lange level drops. Figure 3 is a magninied view oo log-log seale of the level for a time anter a release. In this ngure the Jevel has the small bassal rale of level growth subtracted (to show the eftect of the gas being released) and appears to be following a power-law fuaction of time until between 6 and 10 days have passed. 


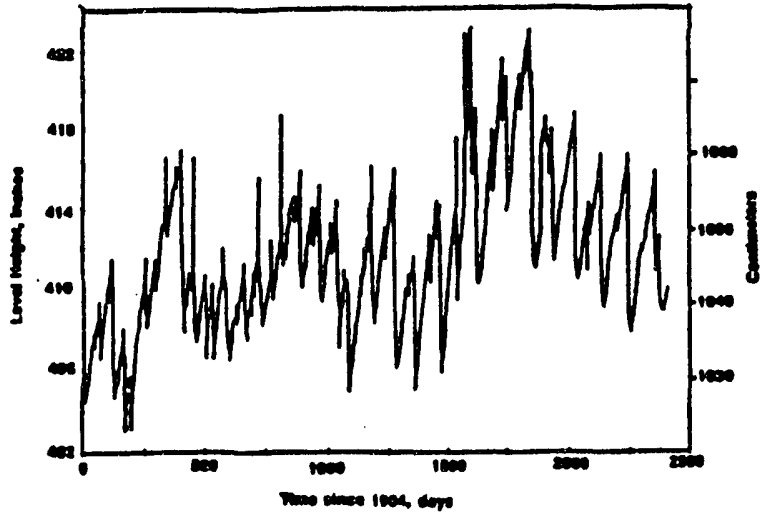

Figure 2 Level Ilistory in Tank 241-5Y-1012

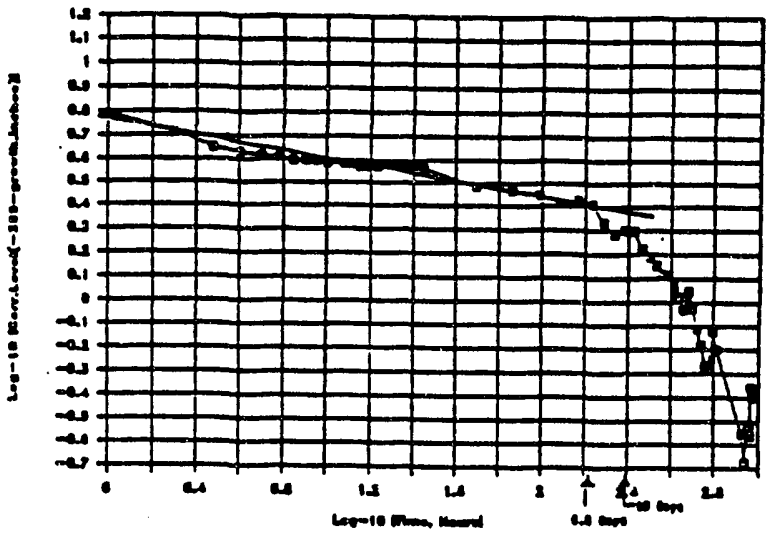

Figure 3. Level Data for Several Days afler the October 24, 1990 Gas Release

\section{B. Temperature}

Figure 4 shows two temperature proflies (before and afler release) token with the single thermocouple stalk during a release in 1990 . Before the release, the temperature shows a worm bulge (100 to $500 \mathrm{~cm}$ in height) in the lower part of the tank; a comstant temperature lnyer in the mid-section of the tank (500 10 $900 \mathrm{~cm})$; and above that $(1000$ to $1200 \mathrm{~cm})$, a rapid temperature drop to the head space, which is rentliated. The temperature bulge was surmised to be caused by the retention of radiouctive deeny heat in a noncoavective Inyer near the bollom of the tank Above that layer is a convective Inyer ( $50010900 \mathrm{~cm}$ in height) in which the cemperature profile is nat because of convection. The temperuture drop to the liead space was thought to be caused by crust about $1.3-\mathrm{m}$ thick at the top of the waste bulk During the release event, the sequence of temperature profiles showed that the temperature bulye in the lower part was removed la about 1 minute, while a warm cempeselure bulge (shown as "Aner eveal" la Migure 4) appeared in the upper part of the tinik. Figure 5 shows the thermal proflile for several dags anter the redeuse eveal. Oae con see that after a few days the tevaperature at the bottom beelas to rise agaia, whlle the top bulge disappeors.

\section{Waste Composiltion and Propertles}

Samples of the waste extrected by the tonk operntors have been analyzed. The waste appears to be a sludge or a slurry and is a highly basic, salurated mixture. The waste consists of a mixture of golution (superantant liquid) and solids contalaing niostly sodium, altrate, altrite, hydroxyh, slumainum, organic cheluting agents, and other constlitueale. The specince gravity of the liguld fraction is 13 to 2.5 and of the solld. contalalag-sind se is 1.6 to 1.7 . The sledre showe a sigailicant shear strenglh and behaves as a thlrotrople noa-Newtonian power-low Auld whea measured for viscosity.

\section{Video and Pholographs}

Still photos of the upper surfuce of the waste in the tank showed a rolled surface of whlle and dark arens. The dark sreas seemed to Iadicate liquid presence. In 1991, block and while videos hove been taken of two releases. These show upwelliags of liquild and gas pushing notsam (and even tank measurement equipmeat) aside. The apwellings are assoclated with pressure pulses in the vent line. The series of upwellings (each of a few seconds duration) last for minutes to hours, and with each upwelling there is a subsequent "Inzzing" of smoller bubbles reaching the surface and bursting.

\section{TIEOIYY OF PARTLLL ROLLOVER GAS RELEASE}

The Inversion of the temperature proflie (Figure 4) was termed "rollover". An Inilial calculation of aa unstable temperature overturn in a cylindrical vessel was performed by Eylere using the bydrodynamic code, TEMPEST. This tro-dimensional simuletion showed the bottom layer rising to the top in several places almost simultaneously. This suggested that complete rollover might not be the preferred mode, and that the sludge might rise in gobs of material; only part of the sludge would rise to the top and relense gases during a given release event. The linies for the temperature overtura and some leatures of the temperature profile were reproduced by the numerical simulation, but the simulation was not detalled enough to handle the separation of the gas phase or to predict the level in the tank subsequeat to the main release.

n R.T. Allemann, LL. Eyler, et al. Stafus. Reonrt on Concentunl Models for Waste Tunk Mechanistic Anilississ Janunre 1921, P'acilic Northwest Loboratorg, Richland, Washington (drall report). 


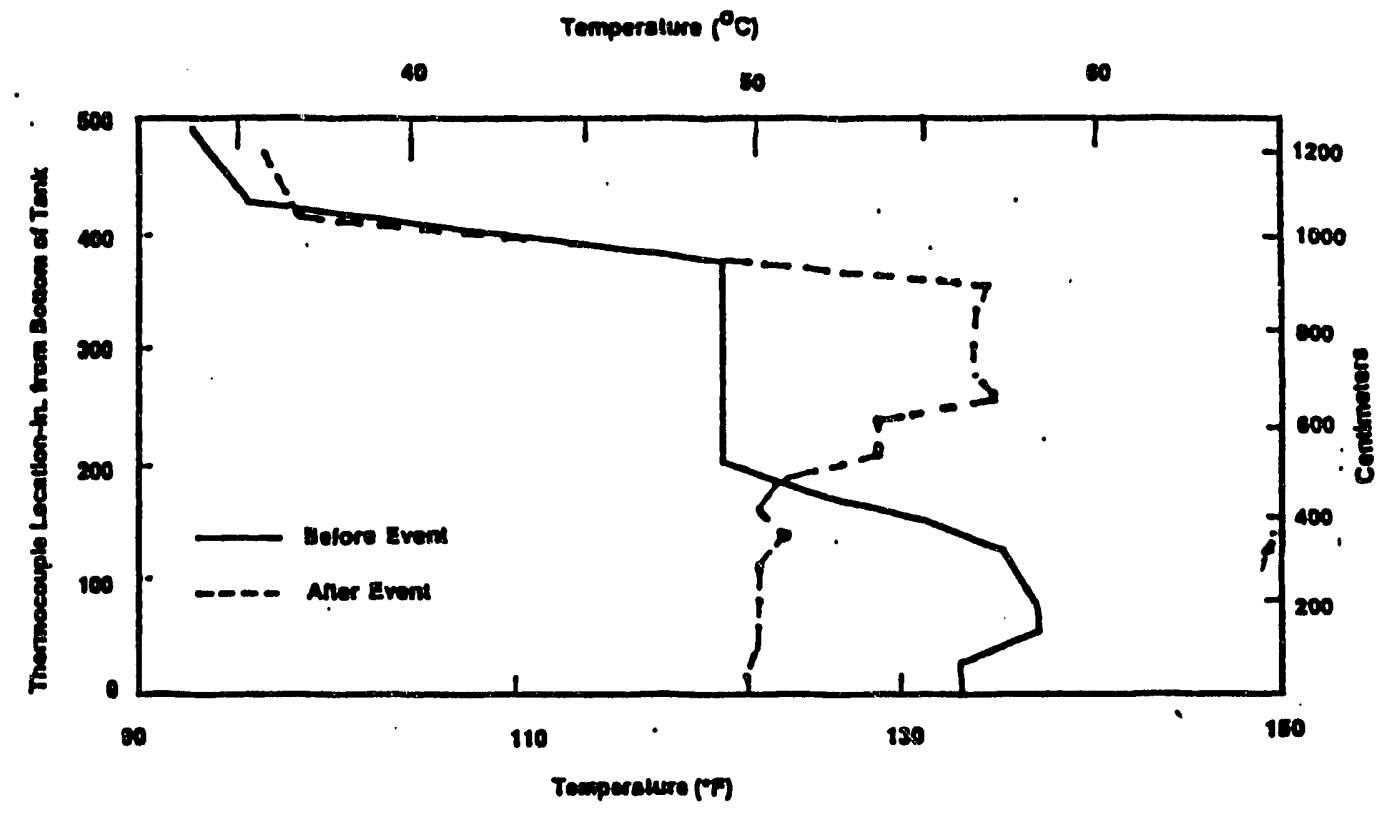

Pigure 4. Temperature Pronles in Tank 241-5Y-101 Before and Amer Oetober 24, 1990 Gas Releuse

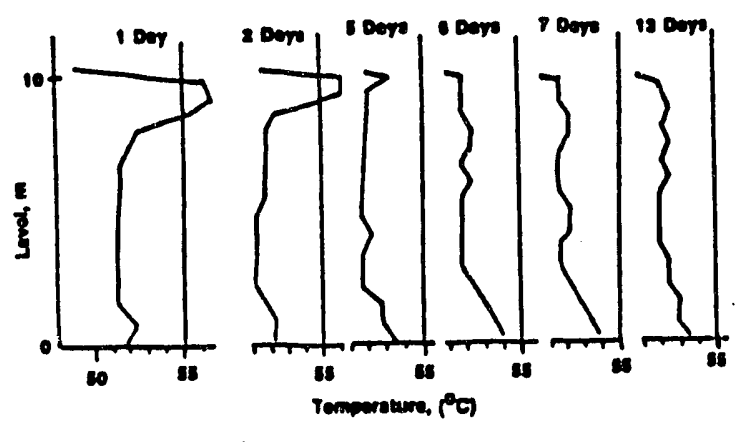

Figure 5. Temperature Profles Several Duys After October 24, 1990 Event

\section{A. The Gob Theory}

A proposed theury of partial rollover that can explain muny of the quantilative and qualitative observitions is colled the "zob theorg". In this theory a portion of the bottom sludge in the tank retains enough of the gas being produced by the woste, that this portion (gnb) breuks loose from the sludige, mass or layer buoyancy overeomes the cohesive forces and viscosity. The gob then rises rapidly to the top of the bulk waste and almost instantly releases the largest bubbles of gas that have already coalesced (or relenses gas rapidly because the gas has expanded and conleseed because the motion has reduced the strength of the sludge matrix). The gas still remaiaing in the gob is smaller size bubbles, percolates ("Irzes") out at a slower rate untll the amonat of gas ean so longer bold the cohesive solid Iractina anoah. Then the gob material beglas to sinks and the remalaing gas is recompresced by bydrostatic pressure.

\section{B. Results of Calculation}

Fhure 6 show the bwoynucy stress and the ytold strength of the in-tank sludge coataining a unlforas anas fraction of gas bubbles. The streagth of the sludge is a function of the rold frectlon, which raries with depth because oi hydrostatic head. The bwojancy lorce of overlying material contributes to a teasile streas at all depths below. This stress has been obtaleed by intecrating the boussinesc' equation of stress contributlons of each layer of sludge Measured values of yjeld strength and specific gravilues were used in the calculation. In the Figure 6 example, the crossover point of the iwo curves is the depth above which the material should pull away. This depth is a function of the properties assumed and the rold fraction. For example, void fruction of 0.3 would allow the material to rtse from a depth of $4.5 \mathrm{~m}$, which would be at the bottom of the weste tank. The actual shape of the parting liae for this material is not yet calculated. If the departure from the power-low relation of the level history shown in Figure 3 is cnused by the compression of gas remaining in the gab (the gas compresses, so the waste levef falls), the volume of that gas can be estimated by assuming a pressure change. From the volume of gas released and the associaled level drop II bas been colculated that the gus released from the tank was retained at a pressure of about 2 atmospheres, which is about midway in the 


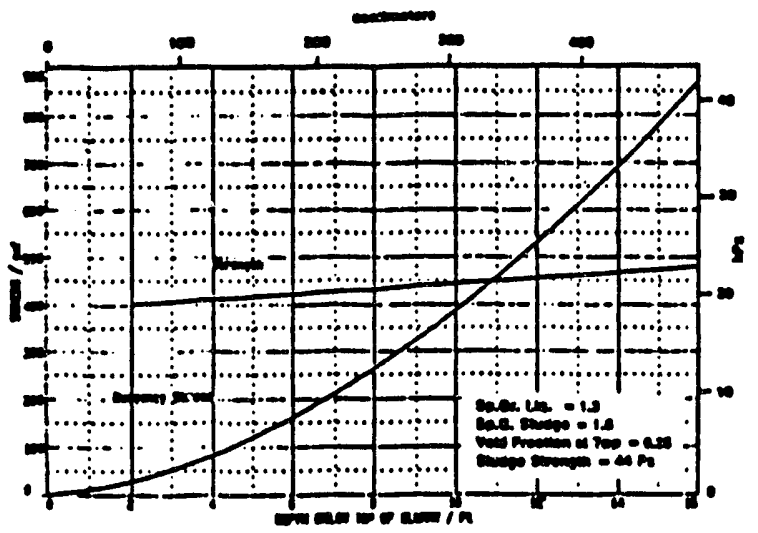

Figure 6. Calculated Bwoyancy Stress and Yield Sireagth of Nonconrective Loyer (Sludge) in Waste Tank

monconrective layer. The level rate change beginaing at the 6 to 10 day time period implies that $22 \mathrm{~m}^{3}$ of gas were compressed. On the basis of llquild and slurry specinc gravilies of 1.3 and 1.6, respectively, the volume that can be supported by this gas is $213 \mathrm{~m}^{3}$. If the gob were a hemisphere, initiully it would have had a radius of $4.6 \mathrm{~m}$, which is about equal to the sludge depth, and would therefore have parted at the boltom of the tank This would explain the fact that the temperature at even the lowest thermocouple changed during the eveat.

Assuming that a rob of this stze would sprend out at the top of the bulk waste to a disk about $1-\mathrm{m}$ thick, the rate of percolation of the remaining gas aner the major release was colculoted. In this colculation a lognornal distributlon of bubble size was assumed and the bubbles were assumed to rise at a terminal velocity dependent un a closed form drag coemicteat solution of bubble motion through a non-Newtonian power-low nuid.4 The power-law coelmeieat of $n=0.75$, measured for the slurm, was wed. The result of this colcuintion gives a rate of gas percolution release very close 10 a power law. This type of gas release can also be inferred from the power-law level decrense of Figure 3. With a choice of mean bubble stze and geometric standard deviation for the parcolating bubbles the tiane at which the gob would begin to sink could be matched; this analysis gave the rate of gas relense shown in Fleure?. The mean bubble size required for the Octaber 1990 event was $2.1 \mathrm{~cm}$. It was interesting to mote that the tank videos taken in August 1991 and December 1991 showed the existence of percolation and that the visible bubbles were estimated to be in this stase renge.

The December 1991 video sbowed a series of upwellings about 10 seconds apart followiag the initial major burst. These may be explained as satellite gobs thut can peal upward once the cohesive material on one side hus broken awray with the main sob. The random nature of the gas release (and level drop) size is probably the result of the compounding of vold frection effects remalaing from previous relenses. Large vold frections can irteser a sob release from shallow depth; these would give the more aumerous small level dropes.

\section{Contrests with Other Theories}

Crust Theory. Initial theories of the episodic release were based on the idea that a solld crust was tropping the gas below it and that the crust would periodically break This theory did aet explala the subsequeatly obtalaed dat of the temperature Inverston. Regnolds" of Westinghouse tianford Compangy sugegested the iden of gas being trapped in the sluder below the crust and the concept of a "rollover". Leter, the measured temperature inversion gave impetus to the concept of a rollower, that is, that the matertal at the botiom of the taak had risen to the top of the bulk as the upper region descended. The preferred mode of this rollover would be depeadent on a form of Rayleigh aumber and might be toroldal, or in rolls covering the width of the cyllindrical tank The fdee of a total rollover was not supported by the heat balance obtained from the

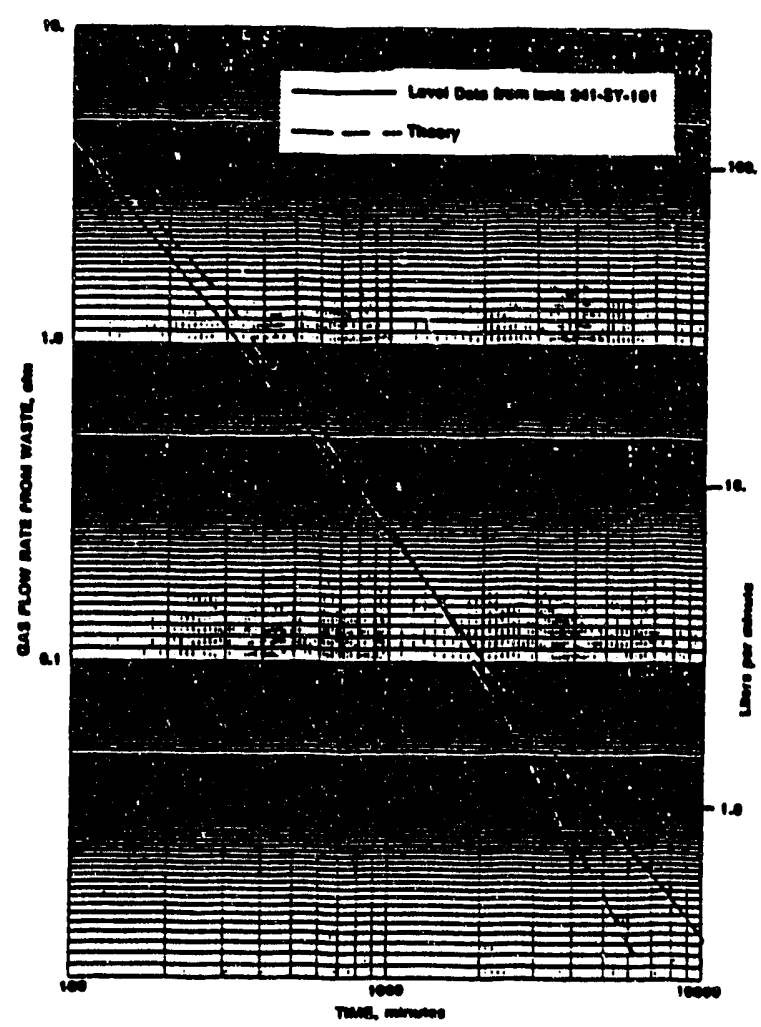

Figure 7. Rate of Gus Relense Subsequent to Main Retease of Octuber 24, 1990 Event 
Thermal profilea. For a brye eveul, inillal heat recovery was 100\%, howner, in profles from a fow bours later, only a $70 \%$ recovery of inllial beat was realized. This Implied that the turnover was not walform across the tante, or that oaly part of the waste was lavolved.

The aumerieal nuld dyaamic simulations that have bees used so far can caleulate the general times for the rollover Itself, but do wol calevlate the subsequeal level changes and ges releases.

Particle Settling Theory. Another bypothesis has the particles of the sludse being corried up by the bubbles by attuchmeat and by viscous drag. The gas relense would then be accompanied by the particles sellling beck down. The reason that the bubbles release suddealy from the partictes is aot clear. In this case, temperefure equaltzation by beat exchange would be extensive and the temperature profle would be smoolh (It is not) Also the material would no longer be warm upon reaching the bottos. Therefore, in this theory the rebullding of the temperature proflie at the bottom observed after a fow days (Figure 5) would be caused by the slumpine of sludee into the repion vacated by the risen material The particle settling theory implies a larger iraction (not mensured) of gas release for un event than does the gob theor). The fraction has aot been calculated for the particle settling theory.

In the gob theory, the cohesiveness of the sludge that is required to account for the retention of gas near the boltom of the balk is nos totally ellminated by the release of some of the gus. The presence of strength, or lack of strength, is important to the techalqwes of mixing the tank for miligation or retrieval.

\section{SUMMARY}

The gob theory of episodic gas release from llanford tank 241-5Y-101 explains quantilatively 1) the phenomena of long-term gas release rate associuled liquidd level drops in the tank, and 2) percolation bubble size Quallitatively the theory explains 1) temperature profile overturn and beginaing of the profile reconstruction, 2) the temperature belance durine a release, 3) the association of a series of apwellings duriag a release, and 4) the varted release slzes. These results bave shown the sensitivity of the projecied phenomenon to the physical properties of the waste slarry. Also, these results point ont the aeed for specilic data conceraing the propertles of the waste slum to verify the.theory and to show how miligation methods would operete to interfere with the physical mechanisms of level growth and of episodic gas release. The theory may be exteaded to explore 1) the dynnmics of the gob motton; 2) deformation of the sludge; and 3) the effects of vartubles such as sludge strength variations, vold fraction, and previous history. New data will be obtained as the tank coatinues 20 be moaltored. These data will serve to help prove, disprove, or reflne the mechanistic theory.
Otber tanks at llanford have axhlbiled some of the fevel growth phesomenon, but the most prominent setion has oceurred in 241-5Y-101. The instrumeatation and observallons that have been made on this tonk have gtrea lasights to the phesomeson and these Insights will rind applicution to other tunks as well.

\section{ACKNOWLEDGEMENT}

This work was conducted by Pacilic Northwest Laboratory for the U.S. Department of Eeerey under Contract DE-AC06-76RLO-:E30 to support the llighLevel Waste Tank Safoty Program activities at Westlaghowse llauford Company. Pacine Norhwest Laboratory is operated for the U.S. Departméat of Eneray by Battelle Memortal lastitute.

\section{REFERENCES}

1. D. M. Stru Waste Sclence Pnnel Mezllna. Februgn 7.8. 1991, INL 7709, Paedine Northwest Laboratory, Richland, Weshiagloa (1991).

2. J. J. BARKER, T. M. BURKG, R. G. CAROTIIERS, and D. A. REYNOLDS, Emlunilon ol Ocinber 24. 1990. Tank 241-5Y-101 Gas Relense Drent WIIC.SD-IVM-PE-041, Westinghouse Ilanford Company, Rlehland, Washington (1991).

3. b. M. DAS, Adrnnerd Soll Mechnnles, Ilenitsphere Publishing Company, New York (1985).

4. A. ACILARYA, R. A MUSIIELKAR, and J. ULBREECIT, "Mechanice of Bubble Molion and Deformation in Non-Newtonian Medig," Chemical Enpineerine Sclence- 32, 863-872 (1977).

5. II. DABAD, G. D. JOIINSON, J. A. LECIIELT, D. A. REYNOLDS, et al, Eralunlion of the Genernilion and Relcase of Binmumuble Cinses in Tank 241-SY-101, WIC-EI'-0517, Westinghuuse Ilanford Company, Richland, Washington (1991). 
WHC-EP-0576

This page intentionally left blank.

D-8 


\section{DISTRIBUTION}

\section{Number of Copies}

\section{OFFSITE}

7

U.S. Department of Energy. Richland Field office

R. E. Gerton (7)

A4-02

Pacific Northmest Laboratories
R. T. Alleman
K7-15
M. R. Kreiter
K7-90
D. M. Strachan
K2-38

28

Westinghouse Hanford Company

R. P. Anantamula

R2-11

H. Babad

G. M. Christensen

R2-78

C. Defigh-Price

H4-21

J. C. Fulton

R2-31

D. G. Hamrick

R2-31

H. D. Harmon

R1-51

D. L. Herting

R2-52

L. L. Humphreys

T6-09

M. N. Islam

G. D. Johnson

N. W. Kirch

C. E. Leach

G. J. Miskho

M. A. Payne

J. G. Propson

D. A. Reynolds

D. C. Richardson

M. H. Shannon

D. E. Simpson

D. D. Stepnewski

Central Files (2)

Information Release Administration (3) TFIC

Publication Services

R2-50

R3-08

R2-78

R2-11

H4-62

R2-50

R2-50

R2-18

R2-11

R2-31

H4-61

B3-55

H4-62

L8-04

RI-08

R1-20

RI-08 
WHC-EP-0576

This page intentionally left blank.

Distr-2 

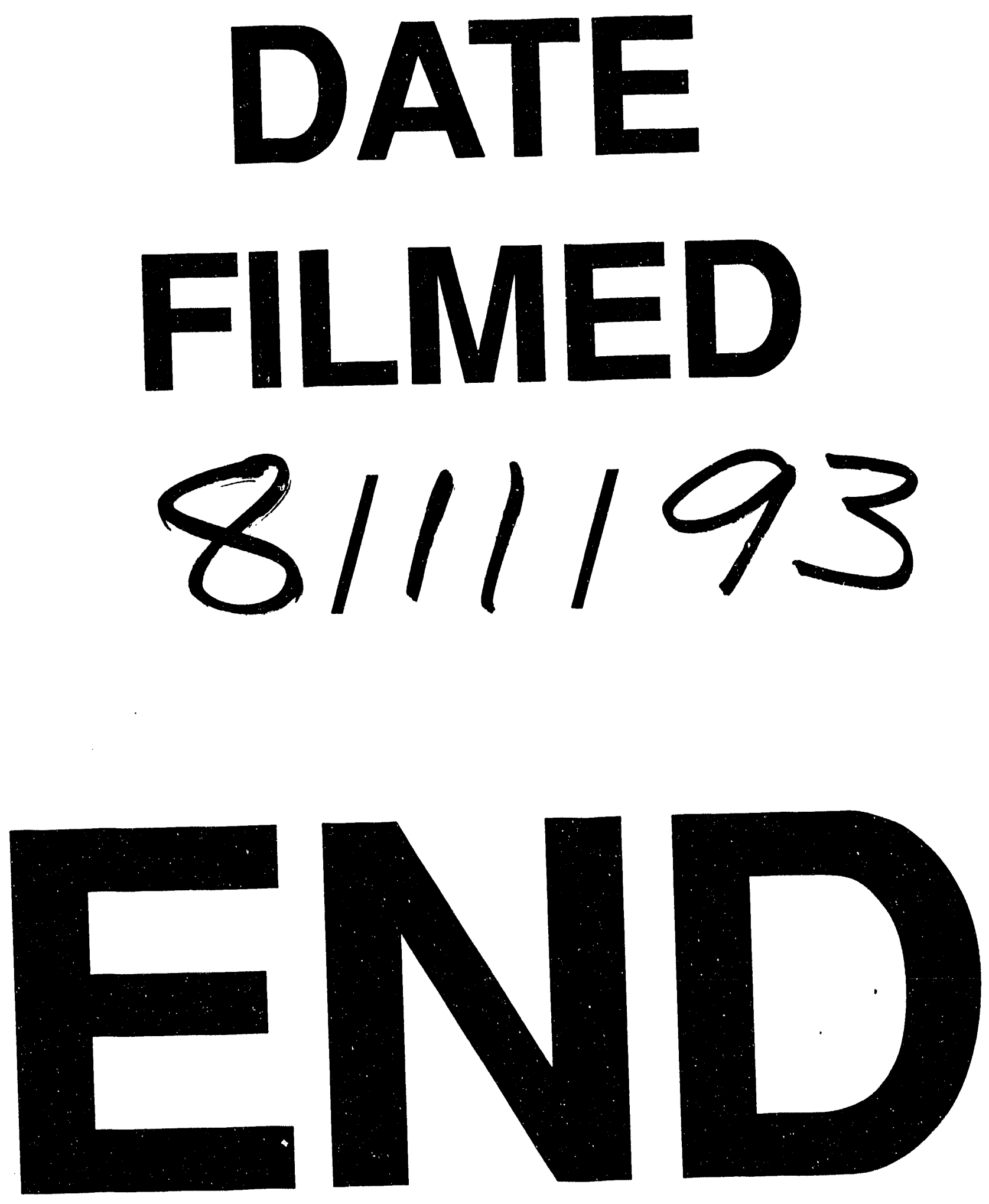
